\title{
Fabrication and performance of a tubular ceria based oxygen transport membrane on a low cost MgO support
}

\author{
D. K Ramachandran ${ }^{1 *}$, M. Søgaard ${ }^{1}$, F.Clemens ${ }^{2}$, J. Gurauskis $^{1}$, A. Kaiser $^{1}$ \\ ${ }^{1}$ Department of Energy Conversion and Storage, Technical University of Denmark, Frederiksborgvej 399, \\ Building 779, DK-4000 Roskilde, Denmark. \\ ${ }^{2}$ EMPA, Swiss Federal Laboratories for Materials Science and Technology, Laboratory for High \\ Performance Ceramics, Ueberlandstrasse 129, CH-8600 Dübendorf, Switzerland \\ *Corresponding author, Tel.:+45 4677 4800; fax: +45 4677 5858. E-mail: dhavaa@gmail.com
}

\begin{abstract}
A $30 \mu \mathrm{m}$ thin-film tubular $\mathrm{CGO}\left(\mathrm{Ce}_{0.9} \mathrm{Gd}_{0.1} \mathrm{O}_{1.95-\delta}\right)$ membrane with catalytic layers on both sides has been prepared by dip-coating on a low cost, porous magnesium oxide ( $\mathrm{MgO}$ ) support. The $\mathrm{MgO}$ support was fabricated through a thermoplastic extrusion process. Support, thin membrane and catalytic layers were sintered in individual steps at temperatures between 1250 to $1300{ }^{\circ} \mathrm{C}$ to achieve a controlled removal of binder and organic additives and to obtain the desired, defect free microstructure. The prepared asymmetric tubular CGO membrane has been tested at elevated temperatures (up to $900{ }^{\circ} \mathrm{C}$ ) using atmospheric air and $\mathrm{N}_{2}, \mathrm{H}_{2}$ for the feed and sweep side respectively. The oxygen permeation was $4 \mathrm{Nml}$ $\mathrm{min}^{-1} \mathrm{~cm}^{-2}$ at $850^{\circ} \mathrm{C}$ using $\mathrm{H}_{2}$ on one side and air on the other side.
\end{abstract}

Keywords; Asymmetric Membrane; Dip-coating; MgO support; CGO membrane; Oxygen flux 


\section{Introduction}

Gadolinium doped Ceria, CGO, is widely used in high temperature electrochemical devices such as solid oxide fuel/electrolysis cells (SOFC/SOEC), membranes and flue gas purification devices. The high phase stability of CGO under both oxidizing and reduction atmospheres and the high ionic conductivity, makes CGO an interesting material for an Oxygen Transport Membrane (OTM). Furthermore, it has been shown CGO becomes a mixed ionic and electronic conductor (MIEC) at high temperatures and low oxygen partial pressure, with sufficiently high electronic conductivity above $800{ }^{\circ} \mathrm{C}$ and under strongly reducing atmosphere [1]. An OTM is a gas-tight component permeable only to oxygen, giving $100 \%$ theoretical selectivity. The use of such membranes to provide oxygen for different industries i.e. steel, cement and syngas production, can improve the energy efficiency in the production cycle and further in some cases facilitate an easier $\mathrm{CO}_{2}$ capture and sequestration. Developing a high performance OTM-system is a challenging task as material development, ceramic processing and system integration must be considered.

The oxygen permeation flux of various fluorite structured membrane materials for wide range of membrane thickness (50 to $2000 \mu \mathrm{m}$ ) have been reported [2]. In order to achieve fluxes that are of commercial interest for most of the large scale applications it is clear that thin film membranes with thicknesses below $<100 \mu \mathrm{m}$ must be prepared. Such thin membrane are typically not mechanically stable. In order to reduce the membrane thickness without sacrificing mechanical properties of the overall component, an asymmetric membrane configuration can overcome the problems associated with

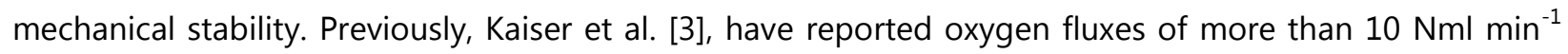

$\mathrm{cm}^{-2}$ at $850{ }^{\circ} \mathrm{C}$ on a $30 \mu \mathrm{m}$ thick planar CGO membrane supported by a Ni-YSZ cermet support. The different layers were prepared by tape casting and subsequent lamination. The CGO membrane showed good thermal and chemical stability at syngas operation conditions.

When the membrane layer gets below a certain characteristic thickness, the catalytic processes on the surface of the membrane might become a limiting factor of the membrane performance. In order to improve the oxygen flux further the surface exchange kinetics have to be enhanced on both sides of the membrane, which is typically done using electro-catalytic materials. $\mathrm{Ni}-\mathrm{Ce}_{0.9} \mathrm{Gd}_{0.1} \mathrm{O}_{1.95}$ (Ni-CGO), ceramicmetal composites (cermet) have been widely used as electro catalytic material in SOFCs $[4,5]$ in which the metallic form of $\mathrm{Ni}$ acts as catalyst for fuel oxidation and provides electronic conductivity, whereas CGO not only acts as a matrix to support the catalyst but it also transports oxygen ions out from the structure [6-8]. Moreover, a Ni-CGO cermet can easily be combined with a CGO membrane instead of using the 
traditional yttria stabilized zirconia (YSZ) due to the thermal expansion coefficients (TEC) of YSZ (i.e. $\sim 10.5 \times 10^{-6} \mathrm{~K}^{-1}$ ) which is significantly lower than that of $\mathrm{CGO}$ and $\mathrm{MgO}$ which was $\sim 12.7 \times 10^{-6} \mathrm{~K}^{-1}$ and $\sim 13.9 \times 10^{-6} \mathrm{~K}^{-1}$ respectively $[9,10]$.

Perovskites structured materials such as $(\mathrm{La}, \mathrm{Sr})(\mathrm{Co}, \mathrm{Fe}) \mathrm{O}_{3}$ have been vastly used as oxygen reduction catalysts in SOFC and for OTMs [11]. It has also been demonstrated that electrodes with very high catalytic activity can be prepared by infiltration of these materials into porous ionic conducting backbone structures [12]. Additionally, Zhao et al. [13], have reported that LSC catalytic layers prepared by this route show remarkable performance in terms of high resistance to thermal cycling and thermal shock due to using of impregnated nano catalytic particles rather than bulk particles.

For the preparation of asymmetric membranes, a planar structure configuration is usually chosen because of the simple fabrication [14]. Changing to a tubular design has some advantages compared to a planar design especially in terms of mechanical strength when the component is in a temperature gradient. Additionally, the sealing of tubular components, especially if high pressure is considered is much less difficult [15]. Some studies on the preparation and testing of an asymmetric tubular perovskite membrane structure have been reported earlier [16]. In these studies identical materials for dense layers and porous supports were mainly used. Recently, Liu et al. [17] demonstrated that a crack-free asymmetric tubular perovskite membrane with a thickness of $20 \mu \mathrm{m}$ could be prepared using extrusion and a spray drying processing step. With the asymmetric design the oxygen flux performance was almost 1.35 times higher than with the symmetric configuration and the membrane was stable under low $\mathrm{pO}_{2}$ conditions over 200 hours. It is evident to see that the membrane performance and stability could be improved by an asymmetric configuration. Moreover, to the author's knowledge studies are not available that deal with the preparation and testing of asymmetric tubular CGO membranes for use in syngas reactors or in similar applications. Hence this work contribute to closing the research gap in this area.

This present work addresses the preparation and characterization of a gastight membrane layer of $\mathrm{Ce}_{0.9} \mathrm{Gd}_{0.1} \mathrm{O}_{1.95-\delta}(\mathrm{CGO} 10)$, supported on a low cost porous $\mathrm{MgO}$ tubular substrate [18]. On each side of the CGO membrane a catalytic layer is present in order to improve the electro-catalytic reaction. The optimization of the de-bindering and sintering cycle is optimized as to allow for an effective removal of binder organics and co-sintering of a defect free asymmetric membrane multi-layer structure. The oxygen permeation flux for the tubular, $\mathrm{MgO}$ supported CGO membrane is measured in the temperature range of $750-900{ }^{\circ} \mathrm{C}$ under conditions relevant for syngas operation. 


\section{Material and methods}

Fig. 1 (a) shows a schematic of the prepared asymmetric tubular membrane architecture in which the porous $\mathrm{MgO}$ support was fabricated using thermoplastic extrusion and the membrane and catalytic layers were prepared through a dip-coating process from stabilized ceramic suspensions. This was followed by impregnation of catalytic material into the porous backbone on the outside of the membrane. Fig. 1 (a) shows schematically the setup of the tubular multilayer membrane. Please notice that the colors in the schematic in Fig 1a do not correspond to the colors of the layers shown in different processing steps in Fig. 1 (b) to (e). This is due to the fact that most of the layers do change color during firing. Fig. 1 (b)-(e) show photographs of tubular membranes after each progressing step, before and after firing (left and right part of the pictures). The process starts from the extrusion of the $\mathrm{MgO}$ tubes, followed by dipcoating and sintering of the catalytic NiO-CGO layer (brown after dip-coating, green in color after firing at $1250{ }^{\circ} \mathrm{C}$, Fig. 1 (c)), membrane layer of CGO (white after dip coating and transparent/green after firing at $1300{ }^{\circ} \mathrm{C}$ Fig. 1 (d)) and porous CGO backbone layer for impregnation of nano particles of LSC (black after dip coating and blue after firing and after LSC impregnation, Fig. 1 (e)).

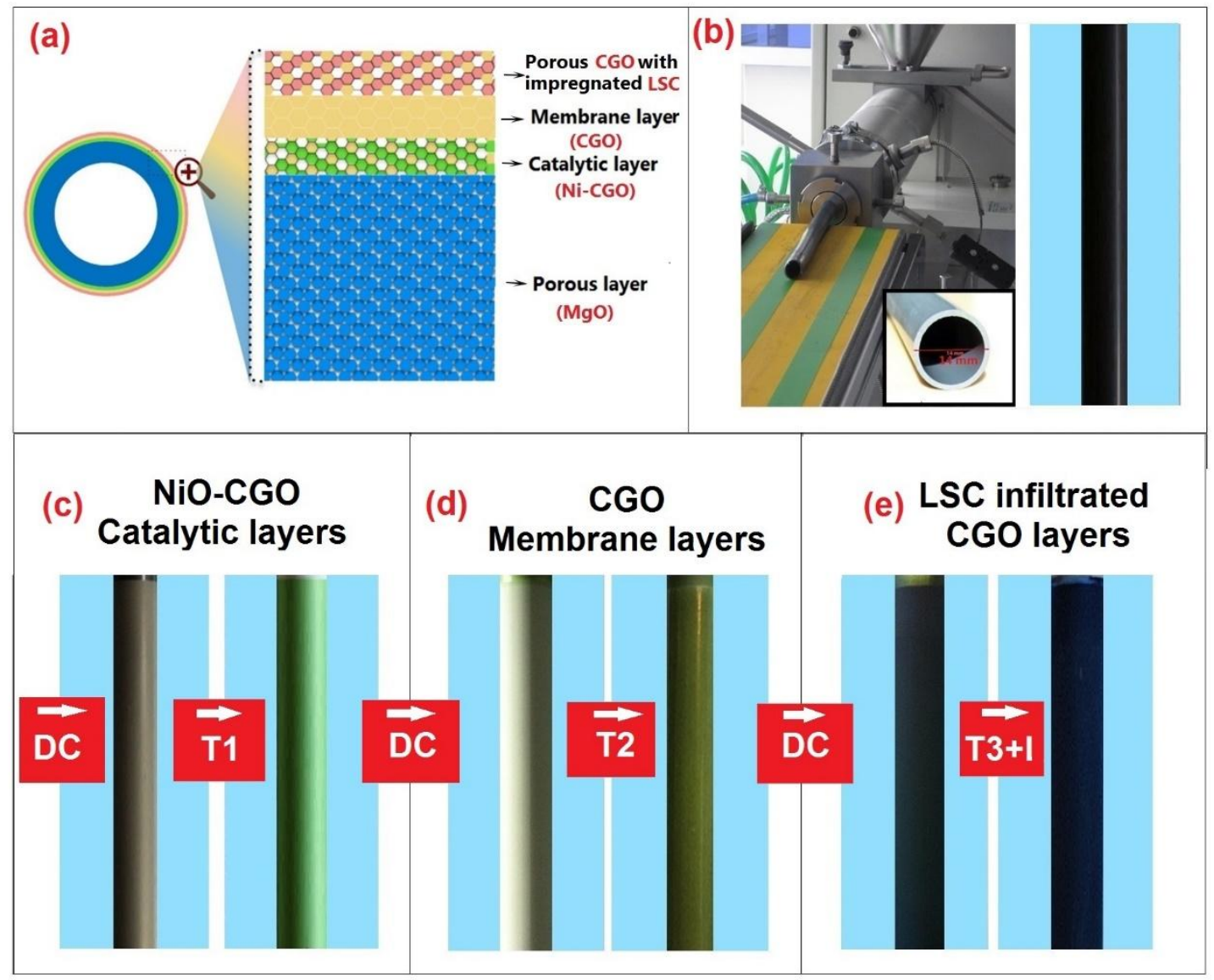


Fig. 1: (a) Schematic of the structure of the asymmetric tubular membrane including the used materials, (b) the thermoplastic extrusion of $\mathrm{MgO}$ tubes (black in green state due to graphite pore former) and the subsequent dip coating and firing steps with (c) MgO tube with dip coated Ni-CGO layer (brown, on left) and after pre-sintering at $\mathrm{T} 1=1250^{\circ} \mathrm{C}$ (green, on right), (d) Dense $\mathrm{CGO}$ membrane layer after dip coating (DC) (white, on left) and sintering at $\mathrm{T} 2=1300{ }^{\circ} \mathrm{C}$ (transparent on green NiO-CGO layer), (e) "porous" CGO layer after dip coating (black, on left) and after sintering at $\mathrm{T} 3=1250^{\circ} \mathrm{C}$ and infiltration (I) with LSC nano particles (blue, on right).

\subsection{Thermoplastic extrusion of MgO support tubes}

The preparation of the tubular $\mathrm{MgO}$ support includes powder processing, kneading, thermoplastic extrusion and finally the thermal de-bindering and sintering. First the MgO powder (Product \# 12R-0801, Inframat Advanced Materials, USA) was pre-calcined at $1000{ }^{\circ} \mathrm{C}$ for $10 \mathrm{~h}$ in order to reduce the surface area of the powder. The pre-calcined MgO powder, graphite powder (TIMREX ${ }^{\circ}$ KS6, TIMCAL, Switzerland), thermoplastic binder (Elvax 250, Du Pont; USA), and paraffin wax (Sigma-Aldrich, USA) as a plasticizer was mixed in a kneader (Linden, Type BK20, Germany). The graphite powder is used as a pore former. The feedstock composition consists of 34 vol.\% MgO, 46 vol.\% thermoplastic binders \& additives and $20 \%$ graphite. The feedstock optimization with respect to the form stability, shrinkage behavior during extrusion and the sintering process as well as additional information on the preparation, can be found in our previous work [19]. The kneaded feedstock was shaped into a tube using a die assembly of $\varnothing$ $=14 \mathrm{~mm}$ outer diameter and $\varnothing=12 \mathrm{~mm}$ inner diameter by using an extruder (Model 19/20DN, Brabender, Germany). An oil bath was used to maintain a temperature of $110^{\circ} \mathrm{C}$ and $100{ }^{\circ} \mathrm{C}$ for the extruder chamber and die head, respectively. An extruder speed of 10 RPM was used during the entire extrusion step as this was found to be the optimal speed with respect to extruded form stability during the processing.

\subsection{Preparation of functional layers}

\subsubsection{Slurry preparation}

Three different slurries have been prepared: i) a CGO slurry for the dense membrane layer (CGO-D) ii) a CGO slurry for the porous infiltration layer on the feed side (CGO-P) iii) a NiO-CGO slurry for the activation layer on the permeate side. The slurry compositions are listed in Table 1. For the rheology 
measurement of dip-coating ceramic suspensions, a rheometer (MCR302, Anton Paar, Sweden) was used. For the dense CGO membrane preparation (slurry CGO-D), a pre-calcined CGO powder (with high solid loading of about 10 vol.\% to ensure full densification of the membrane layer) was dispersed in an ethanol based suspension with polyvinylpyrrolidone (PVP) as dispersant and polyvinylbutyral (PVB) as binder. The resulting slurry for the dip-coating was homogenized by ball milling for $72 \mathrm{~h}$. For the preparation of the catalytic layer on the permeate side, a NiO-CGO (60:40 wt.\%) based cermet was used. This NiO-CGO suspension (total solid loading 5-6 vol.\%) was prepared with low viscosity in order to cover the MgO tube surface evenly and to produce a smooth and thin layer with a thickness of 20 to $30 \mu \mathrm{m}$. For the preparation of a porous catalytic layer on the feed side of the membrane, a CGO-graphite suspension was applied by using dip-coating process. A high graphite content in the slurry of 20 vol-\% was used to create a CGO backbone structure with sufficient porosity after firing. In a subsequent step, an air catalyst in a water based solution of the nitrates corresponding to a nominal composition of $\mathrm{La}_{0.6} \mathrm{Sr}_{0.4} \mathrm{CoO}_{3-\delta}$ (LSC) was prepared. The reason for using this technique is that the catalytic activity can be enhanced by infiltration of nano particles of LSC materials into porous backbone structure [12], For rheology measurements of the developed dip-coating ceramic suspensions, a rheometer (MCR302, Anton Paar, Sweden) was used.

Table 1. Composition of ethanol based dip coating suspensions, used for fabrication of syngas electrode (NiO-CGO), dense membrane layer (CGO-D) and porous backbone for air catalyst infiltration (CGO-P) in asymmetric tubular MgO supported CGO membranes.

\begin{tabular}{lccc}
\hline Components & $\begin{array}{c}\text { NiO-CGO (60:40) } \\
\text { (electrode layer-fuel side) }\end{array}$ & $\begin{array}{c}\text { CGO-D } \\
\text { Membrane layer }\end{array}$ & $\begin{array}{c}\text { CGO-P } \\
\text { (Porous backbone } \\
\text { layer- airside) }\end{array}$ \\
\hline $\begin{array}{l}\text { Nickel oxide } \\
\text { CGO (Low surface area) } \\
\text { pre-calcined at 1000 } \mathrm{C}\end{array}$ & $5-6$ vol.\% & --- & --- \\
$\begin{array}{l}\text { Surfactant, PVP K10 } \\
\text { Graphite }\end{array}$ & 3 vol.\% & 10 vol.\% & $4-5$ vol.\% \\
$\begin{array}{l}\text { Binder, PVB K90 } \\
\text { Viscosity @shear rate of } 100\end{array}$ & --- & 4 vol.\% & 5 vol.\% \\
(mPa.s) & 3 vol.\% & --- & 20 vol.\% \\
\hline
\end{tabular}

\subsubsection{Preparation of the functional layers}

For the dip-coating of the three functional layers, an in-house constructed dip-coater has been used. The dip-coating speed can be controlled accurately by a step engine, thereby allowing a very precise control 
of the thickness and evenness of the coatings. As shown in Fig. 1, the catalytic layer of NiO-CGO was coated on the green $\mathrm{MgO}$ tube and pre-sintered at $1250{ }^{\circ} \mathrm{C}$, followed by dip-coating and sintering of the dense CGO membrane (CGO-M) and finally the porous CGO layer.

The porous MgO layer was prepared by thermoplastic extrusion of the feedstock containing 66 vol.\% of binder organics and fugitive pore former. It is very difficult to simultaneously carry out the binder burn out and ensure the densification of the CGO membrane in the same sintering cycle due to the amount of gasses formed. Therefore in order to remove the organic media, a de-bindering and sintering cycle has been developed which is followed by additional cycles. Fig. $\mathbf{2}$ shows the sintering profile for the $\mathrm{MgO}$ substrate and the three functional layers: the NiO-CGO layer, the dense CGO layer and the porous CGO layer. Heating rates of $0.25 \mathrm{~K} \mathrm{~min}^{-1}$ and $0.5 \mathrm{~K} \mathrm{~min}^{-1}$ were used in the $1^{\text {st }}$ cycle for the de-bindering and the sintering regime, respectively. A holding time of one hour at $300{ }^{\circ} \mathrm{C}, 400^{\circ} \mathrm{C}$ and $670{ }^{\circ} \mathrm{C}$ was implemented during the de-bindering cycle to ensure complete removal of organic matter. The temperature was further raised to $1250{ }^{\circ} \mathrm{C}$ in order to initiate the partial sintering of the NiO-CGO layer and to improve the mechanical strength for safe handling for the subsequent dip-coating.

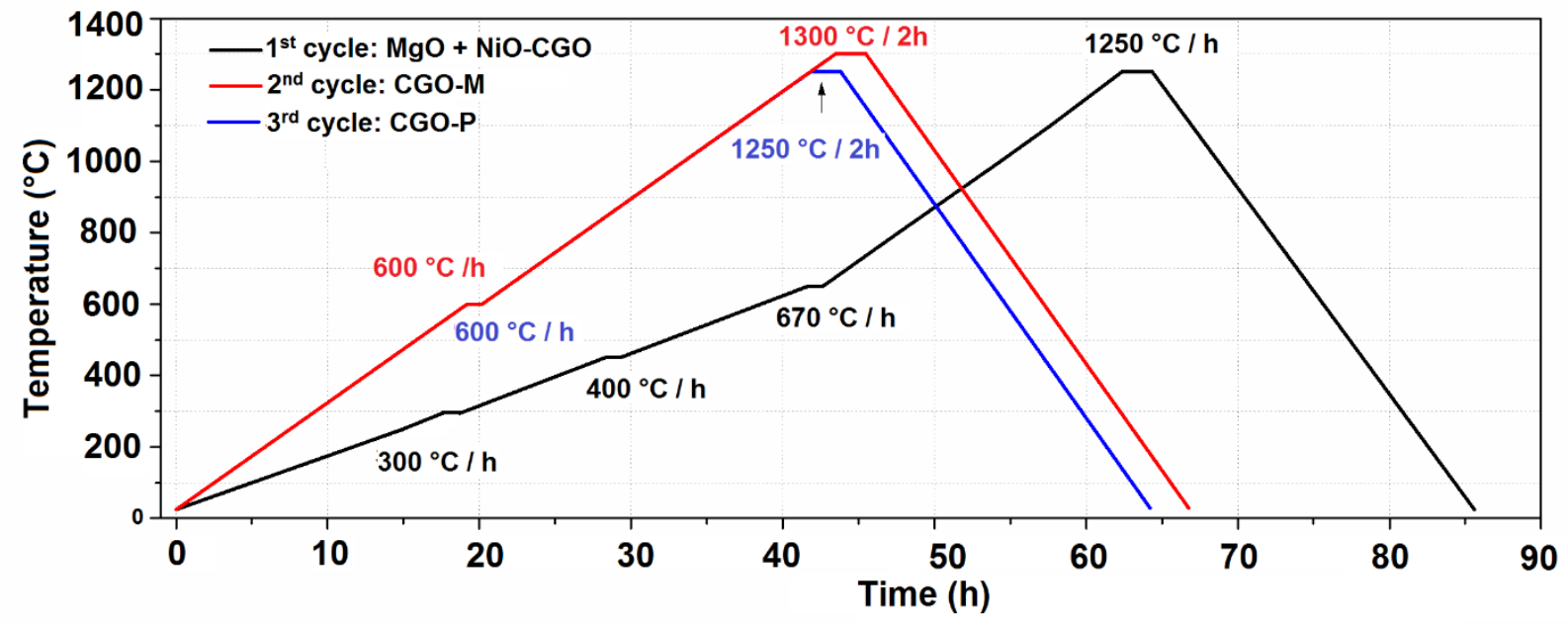

Fig. 2: De-bindering and sintering cycles used for co-sintering of tubular membrane.

Before coating of the membrane CGO layer, the pre-sintered sample was coated again with a single coating of the NiO-CGO suspensions in order to close any pores that may have developed during the presintering of the NiO-CGO layer. The CGO membrane suspension was coated twice in order to improve the chances of gas tightness of the dense membrane layer and to obtain a final sintered thickness of approx. 20 to $30 \mu \mathrm{m}$. After the coating, a heating rate of $0.5 \mathrm{~K} \mathrm{~min}^{-1}$ has been employed for the $2^{\text {nd }}$ cycle and a 
dwelling period of $1 \mathrm{~h}$ at $600{ }^{\circ} \mathrm{C}$ was applied to binder removal and later elevated to $1300{ }^{\circ} \mathrm{C}$ for $2 \mathrm{~h}$ (as shown in Fig. 2).

Finally, the outer (porous) CGO layer is dip-coated on the already sintered CGO dense layer. The component was sintered at $1250{ }^{\circ} \mathrm{C}$ for $2 \mathrm{~h}$. Subsequently, an aqueous solution ( $\mathrm{M}$ ) of the nitrates corresponding to the nominal composition $\left(\mathrm{La}_{0.6} \mathrm{Sr}_{0.4} \mathrm{CoO}_{3-\delta}\right)$ was impregnated into the porous CGO layer 4 times and it was thermally treated at $200{ }^{\circ} \mathrm{C}$ after each impregnation. Finally, the infiltrated catalyst composition was de-bindered at $400^{\circ} \mathrm{C}$ before the membrane testing.

To analyze the shrinkage behavior of the porous and dense layers of the membrane, dilatometry experiments were carried out. For this analysis (an optical dilatometer, TOMMI, Fraunhofer ISC, Würzburg, Germany), warm pressed MgO feedstocks and a pressed pellet of the CGO from dried powder of CGO-M slurry was used after de-bindering at $900{ }^{\circ} \mathrm{C}$. The linear shrinkage $\left(\mathrm{dl} / \mathrm{L}_{0}\right)$ was monitored in situ continuously during the heating and cooling cycles and the shrinkage of the sample was corrected using the thermal expansion coefficient (TEC) determined from the cooling part of the shrinkage curve. Considering the warm pressed pellets isotropic, the relative densities $(\rho)$ are calculated as a function of temperature from optical dilatometry results using the following equation [20].

$$
\rho(T)=\rho_{\mathrm{g}}\left(1-\frac{d l}{L_{0}}\right)^{-3}
$$

where $\rho g$ is the relative density of green sample.

\subsection{Oxygen permeation measurement}

Before the oxygen permeation measurement, the membrane gas tightness has been tested using an inhouse developed equipment. In this equipment the membrane is immersed in ethanol and the inside of the membrane is pressurized with nitrogen to 4 bar. The gas tightness of the membrane was verified as no bubbles could be visually observed.

Oxygen permeation measurements were conducted with the test setup illustrated in Fig. 3. The tubular membrane is connected to alumina tubes via alumina transition pieces. The transition pieces and the sample are mounted at room temperature using a glass ceramic paste consisting of $\mathrm{Na}_{2} \mathrm{O}: 17.8$ mol.\%, $\mathrm{Al}_{2} \mathrm{O}_{3}: 9.4 \mathrm{~mol}$ \%, and $\mathrm{SiO}_{2}: 72.8 \mathrm{~mol} . \%$ and an organic solvent. Upon heating to approximately $900{ }^{\circ} \mathrm{C}$ this glass ceramic paste can flow and seals the transition piece to both the membrane and the alumina tubes. The temperature near both ends of the tubular sample is monitored by two thermocouples located inside 
the transition pieces. Due to the length of the sample and the transition pieces, a temperature difference of approximately $10{ }^{\circ} \mathrm{C}$ was measured at high temperature $\left(900{ }^{\circ} \mathrm{C}\right)$. The alumina tubes connecting the tubular membrane sample were connected to the gas supply system of the rig. The lower alumina tube (permeate/sweep inlet) connects to the gas supply system where a variety of gasses can be prepared/supplied. An in-house constructed oxygen sensor (Nernst sensor) is connected to the inlet of the sweep gas supply.

The upper alumina tube (permeate/sweep outlet), is also connected to an oxygen partial pressure sensor and a mass flow meter. On the feed side of the membrane (outer side of the membrane) a gas flow of 30 $\mathrm{NL} / \mathrm{h}$ air was present during the experiment. On the permeate side of the membrane, different flows of nitrogen/hydrogen mixtures where utilized in order to characterize the membrane performance as a function of the flow rate. The oxygen flux through the membrane was calculated using the mass balance from the flow of the sweep gas and the inlet and outlet oxygen partial pressures of the sweep gas. It should be noted that there is a slight overpressure on the permeate side of the membrane wherefore gaseous oxygen transferred from permeate stream via leaks/pinholes is very limited. The oxygen partial pressure at each sensor is calculated from the Nernst equation. Based on the equilibrium between oxygen, hydrogen and steam, the steam content in the gas at the inlet and outlet can be calculated. The volume flow of steam $\left(\mathrm{H}_{2} \mathrm{O}\right)$ at the inlet and outlet were then used to calculate the oxygen flux as $\mathrm{JO}_{2}=\left(\mathrm{V}_{\mathrm{H}_{2} \mathrm{O}^{-}}^{\text {out }}\right.$ $V_{\mathrm{H}_{2} \mathrm{O}}^{i n} / 2 A$. The procedure is described in more detail in [21]. 


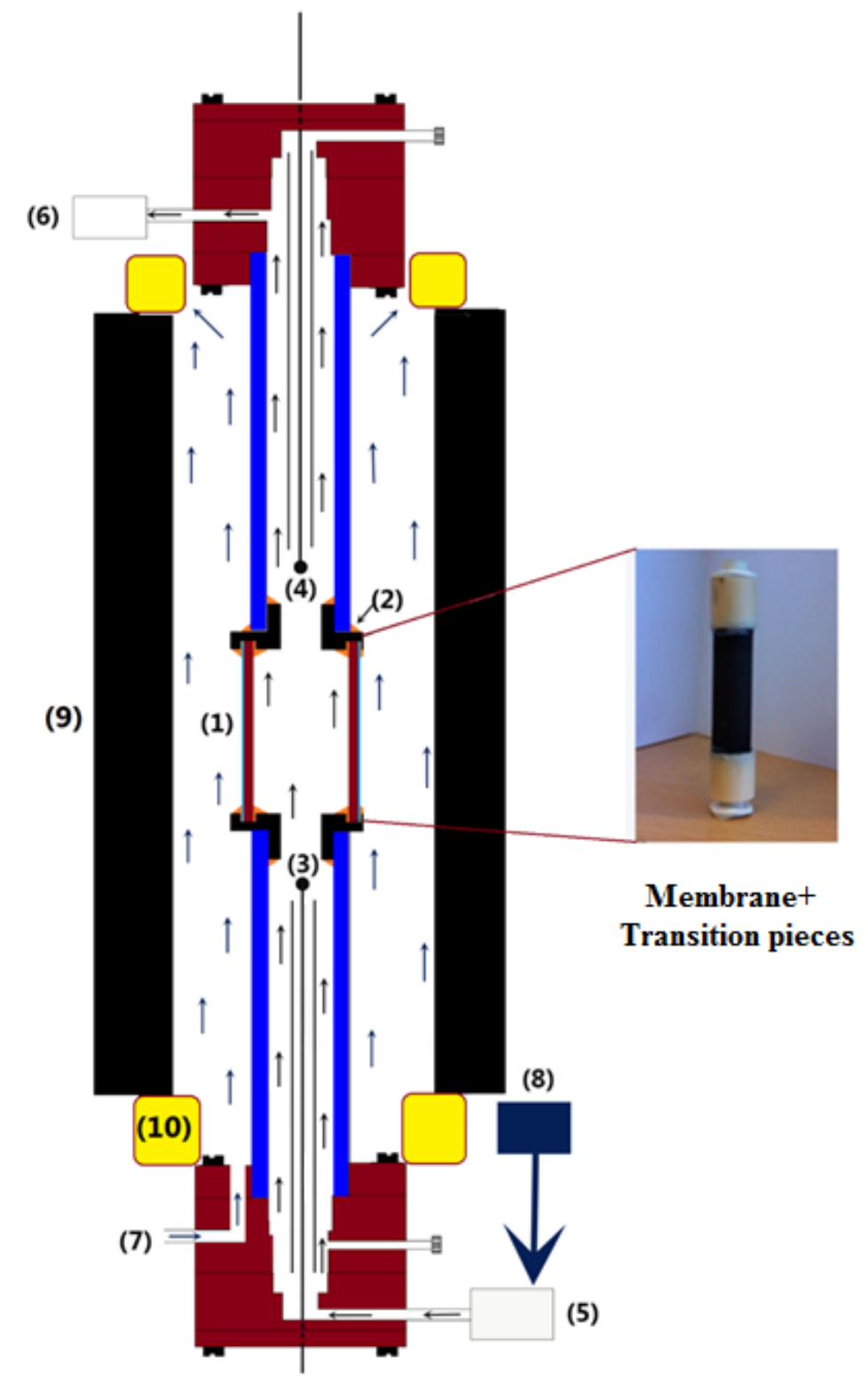

1. Membrane

6. $\mathrm{pO}_{2}$ sensor-outlet

2. Glass sealent

7. Feed inlet

3. TC membrane inlet

8. Gas mixing panel

4. TC membrane outlet

9. Furnace

5. $\mathrm{pO}_{2}$ sensor-inlet

10. Insulation

Fig. 3: Schematic of membrane rig setup. 


\section{Result and discussion}

\subsection{Rheological behavior of CGO-M, NiO-CGO and CGO-P ceramic suspensions for dip-coating}

The rheological behavior of the three suspensions: CGO slurry for the dense membrane layer (CGO-D); CGO slurry for the porous layer (CGO-P); slurry for the catalytic layer (NiO-CGO) have been characterized as to give information on the expected quality of the layer thickness and the smoothness of the coated surface. The viscosity ( $\eta$ ) was calculated from the measured value of the shear stress $(\tau)$ over a range of shear rates $(\gamma)$ from 0 to $100 \mathrm{~s}^{-1}$. Fig. 4 shows that the CGO suspension prepared with high solid loading (CGO-M) for preparation of the dense membrane layer has a shear thinning behavior. The other two slurries for the porous catalytic layers (NiO-CGO and CGO-P) show a very low shear thinning behavior indicating that the coating thickness will only be slightly influenced by the coating speed. At a shear rate of $100 \mathrm{~s}^{-1}$, the CGO slurry with high ceramic loading (CGO-M) shows the highest viscosity of $37 \mathrm{mPa} \mathrm{s}$ followed by NiO-CGO with $19 \mathrm{mPa}$ s and the CGO slurry with $14 \mathrm{mPa}$ s. Due to the lower shear thinning effect of the NiO-CGO and CGO-P slurry, the quality of these suspension is considered suitable as the expected coating surface will smoothen the $\mathrm{MgO}$ support surface to enable the application of the thin film CGO layer (CGO-M).

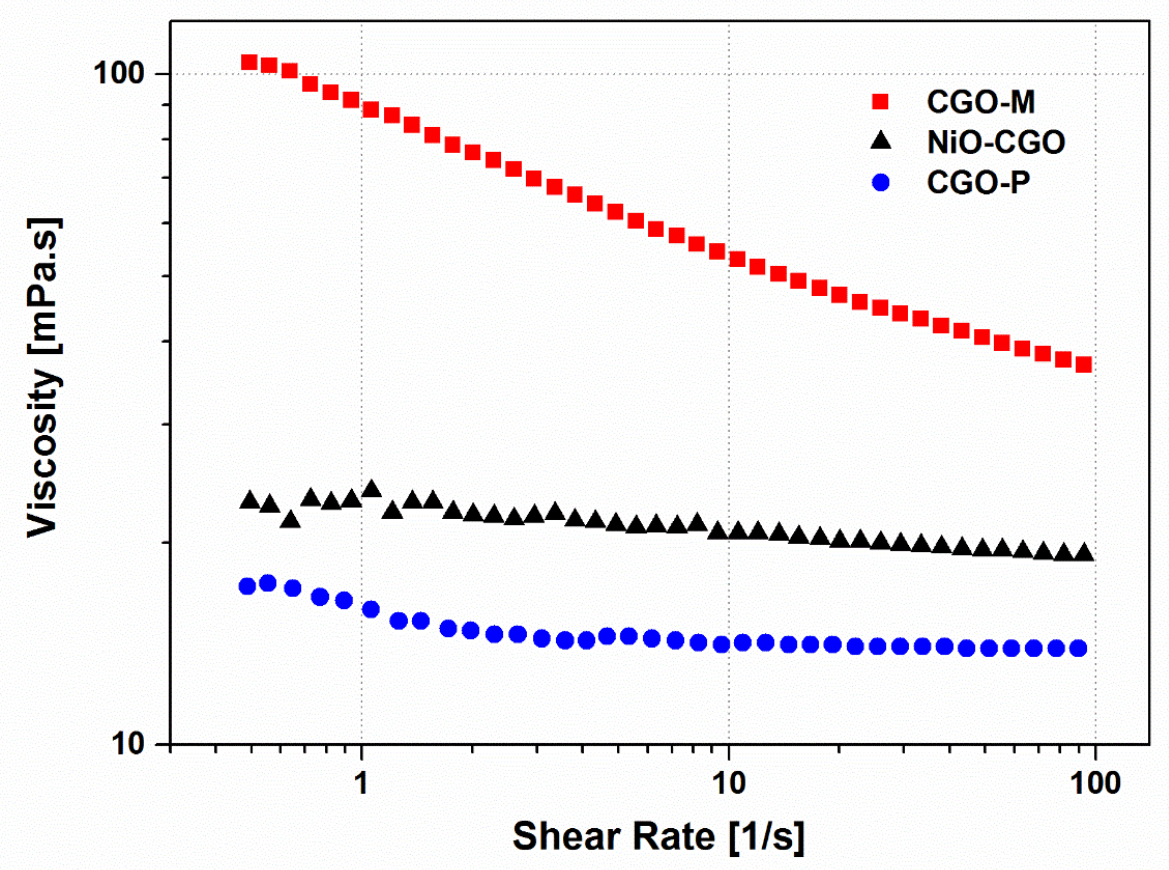


Fig. 4: Viscosity of various ceramic suspensions as function of shear rate.

\subsection{Co-sintering of porous MgO support/dense CGO membrane layer}

An important aspect in the fabrication of asymmetric multi-layers with a porous/dense structure is the cosintering process. In co-sintering, a good match of the shrinkage and strain rate of the membrane structure, consisting of different layers, need to be achieved in order to avoid the development of excessive stresses during sintering which can lead to mechanical failures or warpage in the case of planar structures [22]. For the co-sintering of a tubular support layer of $\mathrm{MgO}$ with a CGO membrane the differences in the starting powders and targeted final densities of the layers need to be considered. A thin membrane layer needs to be fully densified (to achieve $100 \%$ gas tightness) on a sufficiently porous support layer (usually 25 to $40 \%$, depending on support thickness and microstructure).

In the present work the shrinkage, final density and potential distortion of ceramic multilayer systems during the co-sintering process have been measured using optical dilatometry [23-25]. The densification and strain rate development of single green layers of a $\mathrm{MgO}$ extrusion mass and a dip-coating composition (after de-bindering) as function of sintering temperature are shown in Fig. 5 (a) and (b), respectively. 
(a)

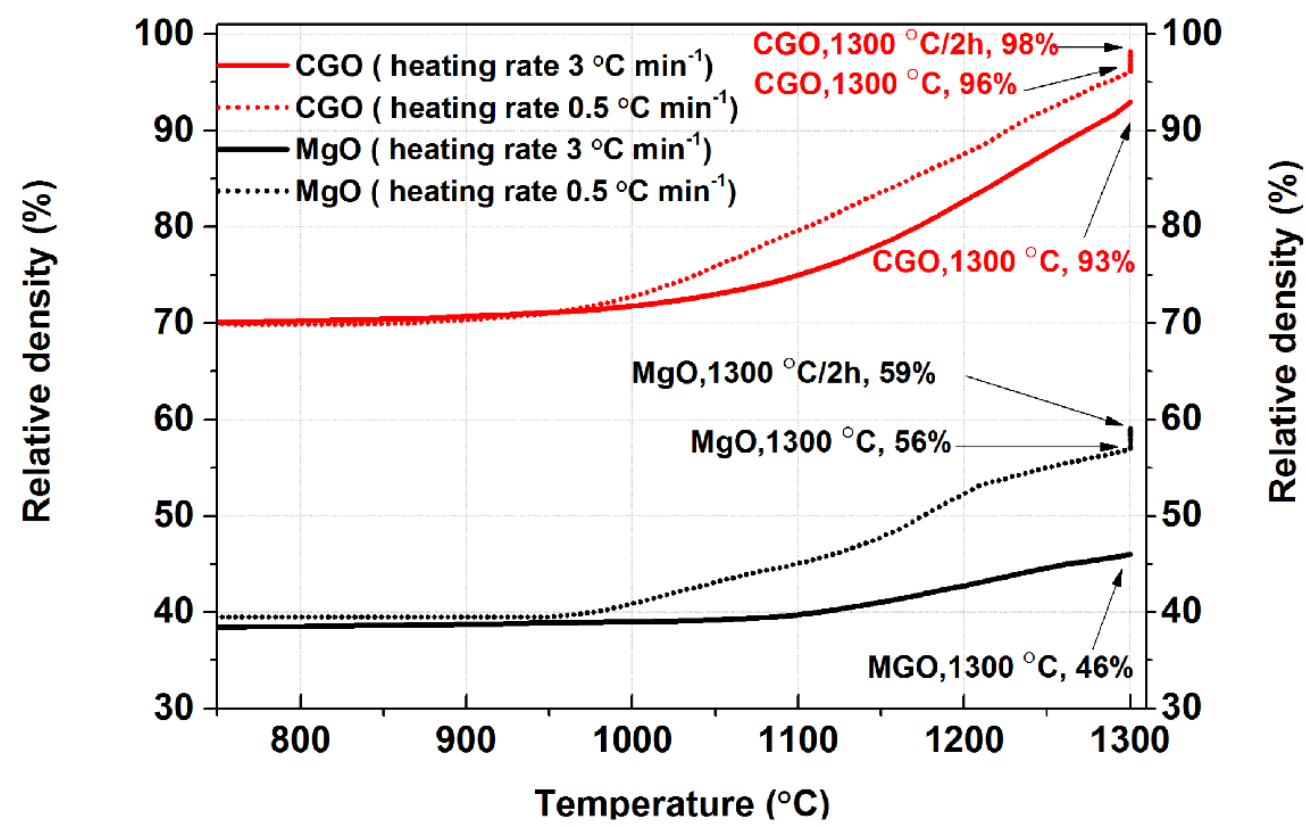

(b)

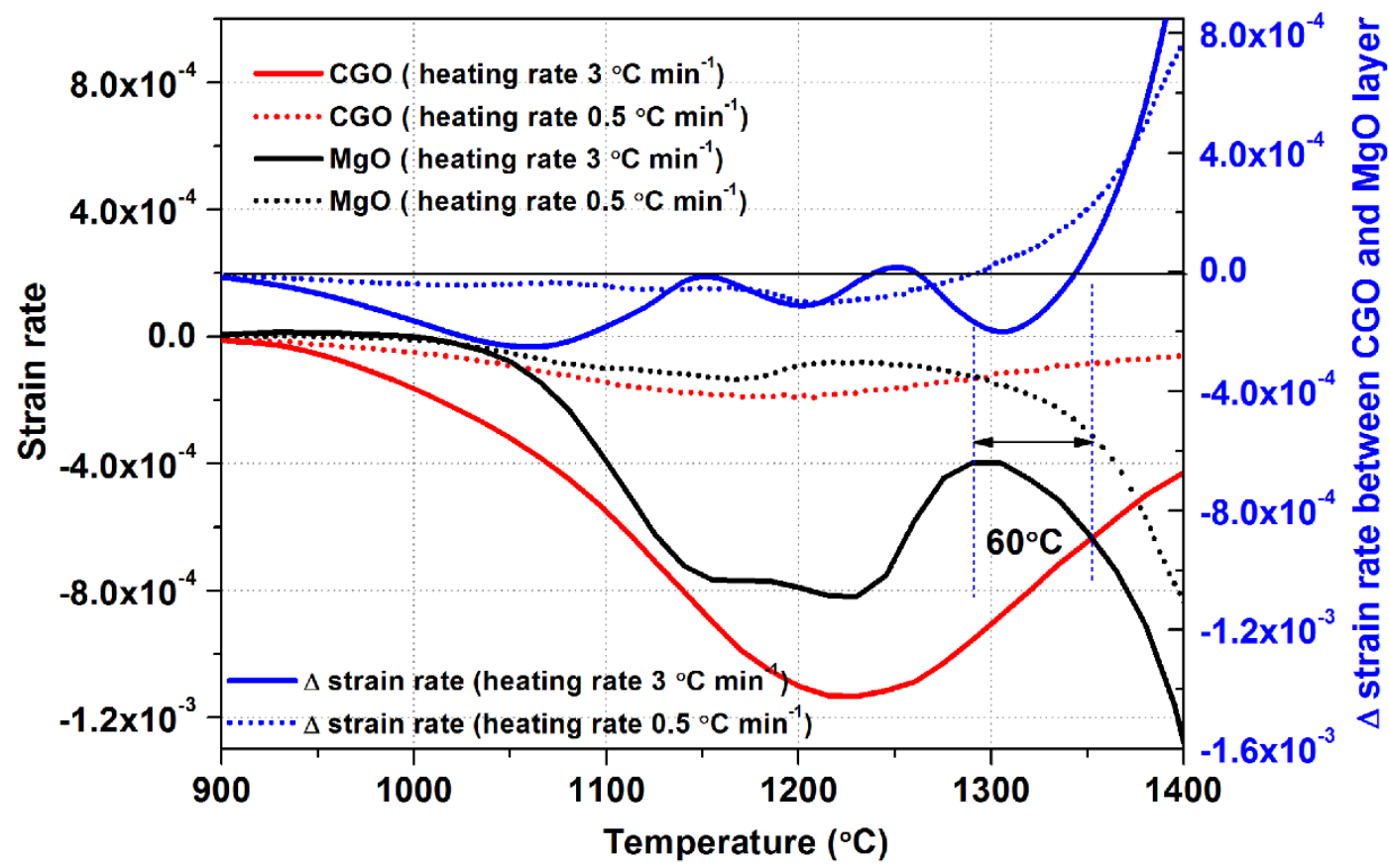

Fig. 5: (a) Densification and (b) strain rates of CGO membrane (CGO-M) and MgO support (MgO-S) layers and, as well as strain rate difference between the two different layers for free sintering as function of 
sintering temperature. Measurements were performed at two different heating rates of $0.5 \mathrm{~K} \mathrm{~min}^{-1}$ (dotted lines): and $3 \mathrm{~K} \mathrm{~min}^{-1}$ (continuous lines) with an optical dilatometer TOMMI [26].

Fig. 5 (a) reveals that the $\mathrm{MgO}$ support structure has a significantly lower starting density (relative density) of about 38-40 \% (or 60-62 \% porosity) compared to a starting density of about $70 \%$ for the CGO membrane layer. The low starting density of the $\mathrm{MgO}$ support (compared to the membrane) is desired and was achieved by the use of thermoplastic binder and graphite as pore formers in the extrusion mass. The densification of the $\mathrm{MgO}$ support structure in a heating cycle is influenced by the heating rate (the total time to reach the final sintering temperature) and the isothermal holding time at the final sintering temperature. Thus, in Fig. $\mathbf{5}(\mathrm{a})$ the $\mathrm{MgO}$ sintered with the slower heating rate $\left(0.5 \mathrm{~K} \mathrm{~min}^{-1}\right)$ reaches almost $10 \%$ higher final density (56\%) compared to the same material sintered with $3 \mathrm{~K} \mathrm{~min}^{-1}$ at a sintering temperature of $1300{ }^{\circ} \mathrm{C}$. Applying additional holding time at $1300^{\circ} \mathrm{C}$ further densifies the structure by approximately $3 \%$. Therefore, faster heating rates would favor more porous support structures. On the other hand, the densification curves of the CGO membrane layer reveal that the fast heating of $3 \mathrm{~K} \mathrm{~min}^{-1}$ to $1300{ }^{\circ} \mathrm{C}$ would only lead to a final density of $93 \%$, densities of $96 \%$ could, however, be achieved with an isothermal holding time of a few hours. A slower heating of the CGO layer would lead to higher density.

Fig. 5 (b) shows the strain rates of the $\mathrm{MgO}$ and $\mathrm{CGO}$ layer at the two different heating rates $(0.5$ and $3 \mathrm{~K}$ $\min ^{-1}$ ) and the calculated strain rate differences for the two layers for both heating rates. From such data the formation of stresses between the layers can be estimated, and together with the shape change of complete, tubular bilayer structures the formation of stresses between the layers can be calculated. Such modeling is reported elsewhere [27] and here we just briefly describe the strain curves and their relevance.

The strain rate difference between the MgO support and the CGO membrane layer in Fig. $\mathbf{5}$ (b) is significantly increasing if the samples are heated faster (heating rate of $3 \mathrm{~K} \mathrm{~min}^{-1}$ compared to $0.5 \mathrm{~K} \mathrm{~min}^{-1}$ ). A larger strain rate difference may drastically increase the risk of the formation of stress-induced defects and delamination. Especially, the larger strain rate difference between the layers in the low temperature sintering regime $\left(900\right.$ to $1100{ }^{\circ} \mathrm{C}$ ) would be critical in a bi-layer structure when the sample is still fragile and sintering necks start to form.

The strain rate curves in Fig. 5 (b) indicate that after the onset of sintering at about $900{ }^{\circ} \mathrm{C}$ the $\mathrm{CGO}$ membrane layer is shrinking faster than the $\mathrm{MgO}$ support until temperatures of about $1300{ }^{\circ} \mathrm{C}$ when the 
CGO layer is getting fully densified and the shrinkage rate of the CGO layer is declining. Above temperatures of about $1300{ }^{\circ} \mathrm{C}$ the $\mathrm{MgO}$ support shrinks faster than the CGO membrane layer (crossing points between the two strain rate curves). Interestingly, this cross over point is shifted from temperatures of $1300{ }^{\circ} \mathrm{C}$ to $1360{ }^{\circ} \mathrm{C}$ if the heating rate is increased from 0.5 to $3 \mathrm{~K} \mathrm{~min}^{-1}$.

Therefore, if the stress levels do not lead to failure in the low temperature sintering region, a co-sintering with a fast heating rate towards a higher final sintering temperature (and shorter isothermal holding times) could lead to a bilayer structure with a porous support structure and a dense CGO layer. Furthermore, according to previous investigations by dilatometry, electron microscopy and mercury porosimetry [19], the densification between 1250 and $1400{ }^{\circ} \mathrm{C}$ is governed by the elimination of smaller submicron sized pores. This leads to shrinkage of the overall structure, but simultaneously also a growth and improved interconnectivity of larger macro pores (introduced by the addition of graphite pore former) which surprisingly resulted in improved pore connectivity and gas permeability of the support structure.

Previous work on such $\mathrm{MgO}$ supports with a porosity of $42 \%$ have shown that for these structures a gas permeability (Darcy) of about $4.2 \times 10^{-16} \mathrm{~m}^{2}$ can be reached [19] which need to be improved to avoid gas transport limitations for membrane layers with high oxygen fluxes above $10 \mathrm{ml} \mathrm{min} \mathrm{cm}^{-2}$. With a specific high temperature mechanical test rig the mechanical strength of extruded MgO support tubes was determined with $77 \mathrm{MPa}$ at room temperature and $60 \mathrm{MPa}$ at $850{ }^{\circ} \mathrm{C}$ [28]. These strength values are considered to be sufficient for the membrane application. Nevertheless, these type of strength measurements need also to be performed on fully assembled MgO supported CGO membranes to exclude a reduction in strength due to defect formation during co-sintering.

\subsection{Microstructure of asymmetric MgO supported CGO membranes}

After successful completion of the co-sintering of the membrane, gas-leakage was tested to ensure that the membrane is free from processing defects. The test verified that the membranes were gas tight (for details on the gas leakage measurements refer to section 2.3). Fig. 6 shows SEM images of thermally etched cross sections of the (a) full membrane, (b) interface of $\mathrm{Ni}-\mathrm{CGO}$ and $\mathrm{MgO}$ porous layer after reduction, (c) dense CGO layer, (d) porous NiO-CGO layer and (e) porous MgO layer. Marco-defects or cracks have not been observed in the sample. Fig. 6 (c) shows a cross section of the CGO layer thermally etched, showing well densified CGO with grain sizes in the range of 0.5 to $1.5 \mu \mathrm{m}$. Fig. 6 (d) shows the porous $\mathrm{Ni}-\mathrm{CGO}$ layer. The grains in this layer are well interconnected with high open porosity and an 
average grain size of 1-1.5 $\mu \mathrm{m}$. The MgO support layer did not show any evidence of anisotropy in the porosity distribution (see Fig. 6 (e)). The measured porosity of the $\mathrm{MgO}$ layer was $42 \%$ and the observed mean grain size was 2-3 $\mu \mathrm{m}$. From Fig. 6 (b), it can be seen that some densification has occurred at the interface due to strong interaction between $\mathrm{NiO}$ and $\mathrm{MgO}$. It is reported in the literature that the $\mathrm{Ni} / \mathrm{MgO}$ phase exhibits high catalytic activity in POM (partial oxidation of methane) operation as elemental nickel can be dispersed uniformly in the interface and eventually enhance the catalytic reaction [29]. Hence, the occurrence of densification in the interface will not affect the membrane performance. On the other hand it also improves the mechanical stability between the interfaces of the $\mathrm{MgO}$ and the $\mathrm{Ni}$-CGO layers which was confirmed by SEM image shown in Error! Reference source not found. in which the crack was observed inside Ni-CGO layer and not in the interface. Table 2 shows the mean thicknesses of the membrane functional layer measured from SEM cross sections.

Table 2. The measured thicknesses of functional layers through SEM images

\begin{tabular}{ccccc}
\hline Layer & MgO & Ni-CGO & CGO-M & CGO-P \\
\hline $\begin{array}{c}\text { Thickness } \\
(\mu \mathrm{m})\end{array}$ & $819 \pm 11$ & $28 \pm 0.6$ & $31 \pm 0.5$ & $23 \pm 1.0$ \\
\hline
\end{tabular}




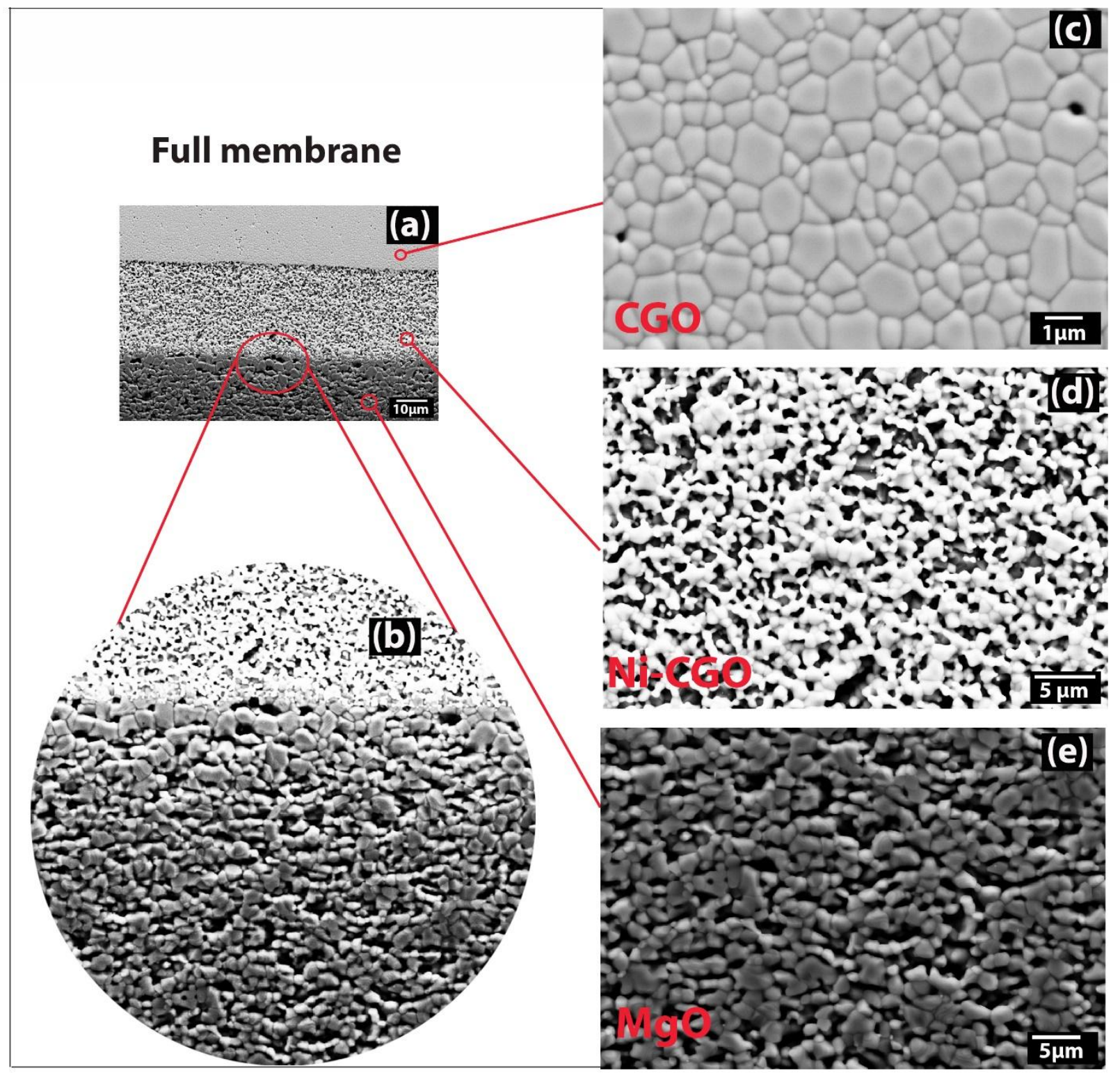

Fig. 6: SEM Micrographs of thermally etched surfaces of three different layers (a) full membrane, (b) interface of the $\mathrm{Ni}-\mathrm{CGO}$ and $\mathrm{MgO}$ porous layer after reduction, (c) dense CGO layer, (d) porous NiO-CGO layer and (e) porous MgO layer.

3.4 Oxygen flux measurements in asymmetric MgO supported CGO membranes 
The performance of fully assembled, asymmetric multi-layer membranes based on $\mathrm{MgO}$ support and the CGO membrane and catalytic layers was finally determined by oxygen permeation measurements, as described in section 2.3 .

For testing the quality of the sealing (between the membrane sample and the transition pieces connecting it with the test rig), the test rig was first heated with $500 \mathrm{Nml} \mathrm{min}^{-1}$ air on the outside of the tube to a temperature of $917^{\circ} \mathrm{C}$ and then cooled to $650^{\circ} \mathrm{C}$. At $652{ }^{\circ} \mathrm{C}$ nitrogen was flowed on the inside of the tube with $100 \mathrm{Nml} \mathrm{min}{ }^{-1}$. The $\mathrm{pO}_{2}$ of the inlet was $2.6 \times 10^{-5}$ atm and the outlet showed a $\mathrm{pO}_{2}$ of $2.5 \times 10^{-4}$ atm, corresponding to a flux of $2.1 \times 10^{-3} \mathrm{Nml} \mathrm{min}^{-1} \mathrm{~cm}^{-2}$. The low oxygen flux indicates that as expected the CGO membrane does not have high electronic conductivity at relatively oxidizing conditions at low temperature and also shows that only small amounts of oxygen leaks into the permeate stream. Also the clear thermal dependence of the flux described in the following can only be obtained if the leakage is very small.

By subjecting the CGO membrane to very fast changes in the oxygen partial presseure one can risk failure due to the chemical expansion. A slow change is therefore preferred as the membrane may relax to some extend via creep. The membrane was therefore first reduced with humidified hydrogen (app. $3 \%$ ) diluted with nitrogen at $650^{\circ} \mathrm{C}$. This was followed by varying the temperature and increasing the hydrogen flow and decreasing the nitrogen flow (see Fig. 7). Fig. 7 shows the oxygen flux of the membrane as a function of the reciprocal temperature for different flows of nitrogen and humidified hydrogen. At approximately $800^{\circ} \mathrm{C}$ the gas mixture was changed from $50 \mathrm{Nml} \mathrm{H}_{2}: 50 \mathrm{Nml} \mathrm{N}_{2}$ to $100 \mathrm{Nml} \mathrm{H}_{2}: 50 \mathrm{Nml} \mathrm{N}_{2}$. This result in an increase in the oxygen flux and is marked on Fig. 7. as an activation of the membrane. The activation is attributed to an increased performance of the permeate activation layer containing $\mathrm{Ni}$ and it is not considered unlikely that it is first at this point the permeate activation layer is fully reduced. There is a clear thermal dependence of the oxygen flux and in pure hydrogen the activation energy of the flux is $82.3 \mathrm{~kJ} \mathrm{~mol}^{-1}$. It is clearly seen that for an increasing inlet hydrogen concentration the oxygen flux also increases, which is attributed to an increase in driving force over the membrane resulting from the increased hydrogen concentration present in the permeate activation layer. 


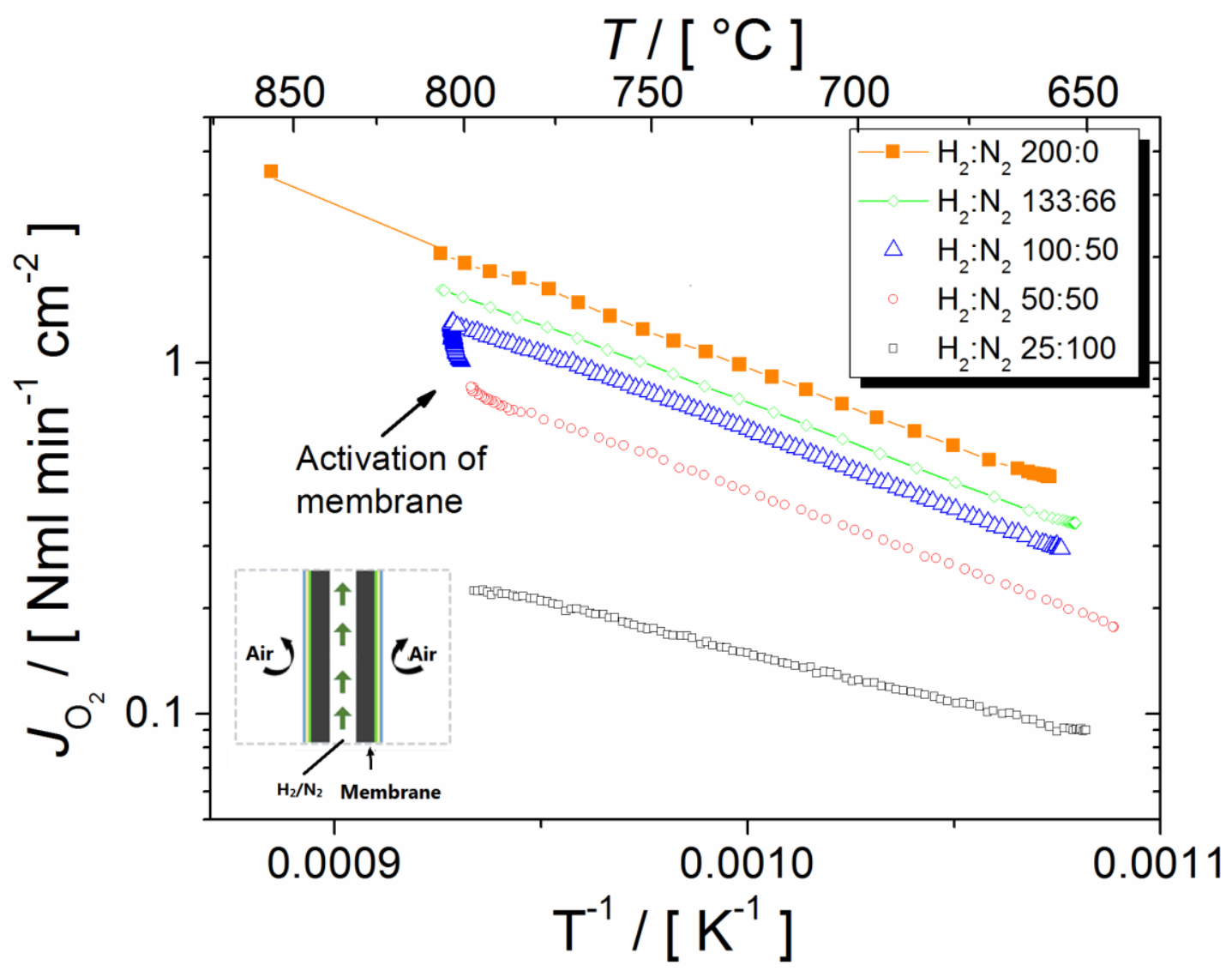

Fig. 7: Flux as function of reciprocal temperature for different hydrogen/nitrogen mixtures. The numbers

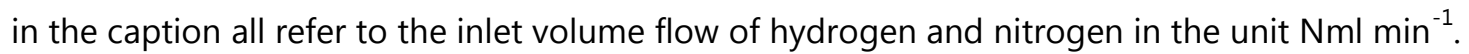

The membrane was also heated to higher temperatures than $856{ }^{\circ} \mathrm{C}$ in pure hydrogen. However, this resulted in significant condensation in the tubing leading to an unstable signal on the $\mathrm{pO}_{2}$-sensor downstream the membrane, wherefore the flux values are highly scattered. There was, however, nothing that indicated that the Arrhenius dependency observed for the oxygen flux (see Fig. 7) changed. The membrane was held for approximately $80 \mathrm{~h}$ in pure hydrogen at $856^{\circ} \mathrm{C}\left( \pm 2{ }^{\circ} \mathrm{C}\right)$ without a measurable degradation in the flux.

Heating from $856{ }^{\circ} \mathrm{C}$ to $920^{\circ} \mathrm{C}$ also resulted in a significantly higher flux, however, this was followed by a rapid deterioration of the flux, to a level below the $856^{\circ} \mathrm{C}$ level. This large decrease is tentatively assigned to a coarsening effect of the Ni-CGO layer on the permeate side of the membrane. As it has previously been shown [30] that a redox-cycling of the anode of a solid oxide fuel cell can lead to an improved performance, this was also tried here. The sample was cooled to $650{ }^{\circ} \mathrm{C}$ and the anode was oxidized with air (approximately $24 \mathrm{~h}$ ) and subsequently reduced again with hydrogen. Fig. 8 shows the flux as a 
function of reciprocal absolute temperature prior to the high temperature treatment, after the high temperature treatment and after the redox-cycle. The permeate gas is in all cases $3 \%$ humidified hydrogen. It is clear that the redox-cycling of the permeate Ni-CGO layer improves the oxygen flux through the membrane dramatically from $0.5 \mathrm{Nml} \mathrm{min}^{-1} \mathrm{~cm}^{-2}$ to $1.4 \mathrm{Nml} \mathrm{min}{ }^{-1} \mathrm{~cm}^{-2}$ at $660{ }^{\circ} \mathrm{C}$. Interestingly the activation energy changes from $68.6 \mathrm{~kJ} \mathrm{~mol}^{-1}$ (after the high temperature treatment) to $53.3 \mathrm{~kJ} \mathrm{~mol}^{-1}$ (after the redox-cycle). The flux reported in Fig. $\mathbf{7}$ is thus to a large extend limited by the Ni-activation layer on the permeate side of the membrane. The observed activation energy of $53.3 \mathrm{~kJ} \mathrm{~mol}^{-1}$ is significantly below that of both typical anode processes and cathode processes [12,31]. It is in the range of theat expected for ionic conduction through the CGO membrane, however, it seems unlikely that the flux is limited by the ionic conductivity through the membrane [32], It is more likely that the low activation energy is an artifact due to the $\mathrm{Ni}$-electrode re-coarsening when increasing the temperature.

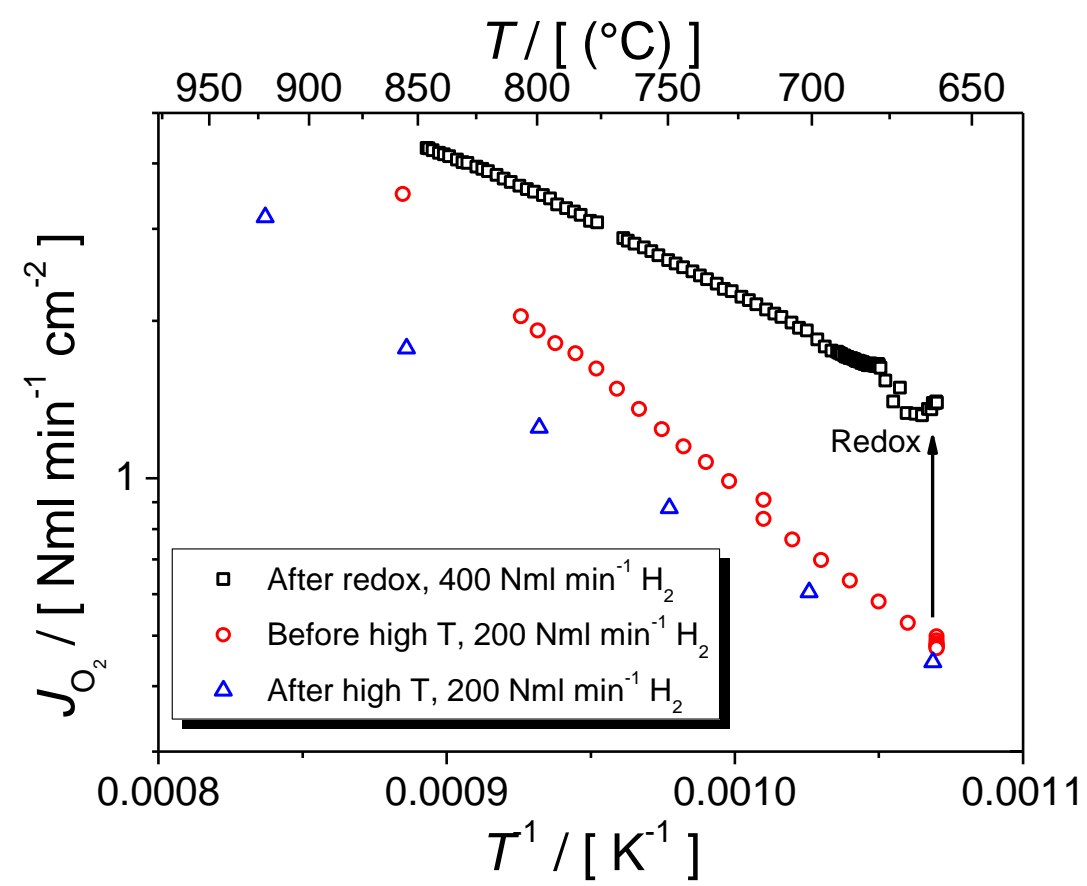

Fig. 8: Flux as a function of reciprocal temperature for three measurement series. Before a high temperature heat treatment at $920^{\circ} \mathrm{C}$, after a high temperature treatment at $930{ }^{\circ} \mathrm{C}$ and finally after the high temperature treatment but after a redox-cycling (air for $24 \mathrm{~h}$ ) of the membrane component at 650 ${ }^{\circ} \mathrm{C}$. 


\section{Conclusion}

An asymmetric tubular CGO membrane has successfully been prepared by an extrusion and dip-coating process. A gas-tight CGO membrane with a thickness of about $30 \mu \mathrm{m}$ was obtained. The optimized debindering and sintering regime with a very slow heating rate of $0.25 \mathrm{~K} \mathrm{~min}^{-1}$ and $0.5 \mathrm{~K} \mathrm{~min}^{-1}$ was used to achieve gas tight thin membranes and desired porosity within catalytic and porous support layers. The $\mathrm{MgO}$ supported asymmetric CGO membrane resulted in an oxygen permeation flux of $3.5 \mathrm{Nml} \mathrm{min} \mathrm{cm}^{-1}$ at temperature of $856^{\circ} \mathrm{C}$ with sweep gas $\left(\mathrm{H}_{2}\right)$ at a flow rate of $200 \mathrm{Nml} \mathrm{min}{ }^{-1}$. A redox-cycle of the $\mathrm{Ni}-\mathrm{CGO}$ catalytic layer improved the permeation flux of the membrane, reaching $4 \mathrm{Nml} \mathrm{min}{ }^{-1} \mathrm{~cm}^{2}$ at $850{ }^{\circ} \mathrm{C}$. A decrease of activation energy suggest that this improvement in performance is due to an improved catalytic activity of the $\mathrm{Ni}$-CGO structure after redox-cycle.

\section{Acknowledgement}

The authors would like to thank the Danish Council for Independent Research Technology and Production Sciences (FTP) which is part of The Danish Agency for Science, Technology and Innovation (FI) (Project \# 09-072888) for sponsoring the OPTIMAC research work. 


\section{References}

[1] S. Wang, T. Kobayashi, M. Dokiya, T. Hashimoto, J.E. Soc, Electrical and Ionic Conductivity of Gd Doped Ceria Electrical and Ionic Conductivity of Gd-Doped Ceria, J. Electrochem. Soc. 147 (2000) 3606-3609.

[2] J. Sunarso, S. Baumann, J.M. Serra, W.A. Meulenberg, S. Liu, Y.S. Lin, et al., Mixed ionic-electronic conducting (MIEC) ceramic-based membranes for oxygen separation, J. Memb. Sci. 320 (2008) 1341.

[3] A. Kaiser, et al., Evaluation of thin film ceria membranes for syngas membrane reactorsPreparation, characterization and testing, J. Memb. Sci. 378 (2011) 51-60.

[4] P.I. Cowin, C.T.G. Petit, R. Lan, J.T.S. Irvine, S. Tao, Recent Progress in the Development of Anode Materials for Solid Oxide Fuel Cells, (2011) 314-332.

[5] B. Steele*, Materials for IT-SOFC stacks 35 years R\&D: the inevitability of gradualness?, Solid State Ionics. 134 (2000) 3-20. doi:10.1016/S0167-2738(00)00709-8.

[6] W.Z. Zhu, S.C. Deevi, A review on the status of anode materials for solid oxide fuel cells, 362 (2003) 228-239. doi:10.1016/S0921-5093(03)00620-8.

[7] S.P. Jiang, S.H. Chan, A review of anode materials development in solid oxide fuel cells, J. Mater. Sci. 39 (2004) 4405-4439. doi:10.1023/B:JMSC.0000034135.52164.6b.

[8] D. a. Macedo, G.L. Souza, B. Cela, C. a. Paskocimas, A.E. Martinelli, F.M.L. Figueiredo, et al., A versatile route for the preparation of $\mathrm{Ni}-\mathrm{CGO}$ cermets from nanocomposite powders, Ceram. Int. 39 (2013) 4321-4328. doi:10.1016/j.ceramint.2012.11.014.

[9] F. Jtilich, D.- Jtilich, Thermal Expansion of SOFC Materials, Ionics (Kiel). 5 (1999) 129-139.

[10] Y. Shiratori, YSZ-MgO composite electrolyte with adjusted thermal expansion coefficient to other SOFC components, Solid State Ionics. 164 (2003) 27-33. doi:10.1016/j.ssi.2003.08.019.

[11] A. Petric, P. Huang, F. Tietz, Evaluation of $\mathrm{La}-\mathrm{Sr}-\mathrm{Co}-\mathrm{Fe}-\mathrm{O}$ perovskites for solid oxide fuel cells and gas separation membranes, 135 (2000) 719-725.

[12] A. Samson, M. Sogaard, R. Knibbe, N. Bonanos, High Performance Cathodes for Solid Oxide Fuel Cells Prepared by Infiltration of La0.6Sr0.4CoO3- $\delta$ into Gd-Doped Ceria, J. Electrochem. Soc. 158 (2011) 650. doi:10.1149/1.3571249.

[13] B.F. Zhao, R. Peng, C. Xia, LSC-based electrode with high durability for IT-SOFCs, Fuel Cells Bull. 2 (2008) 12-16. doi:DOI: 10.1016/S1464-2859(08)70106-8.

[14] S. Baumann, W.A. Meulenberg, H.P. Buchkremer, Feature article Manufacturing strategies for asymmetric ceramic membranes for efficient separation of oxygen from air, J. Eur. Ceram. Soc. 33 (2013) 1251-1261. doi:10.1016/j.jeurceramsoc.2012.12.005. 
[15] U.-J. Yun, J.-W. Lee, S.-B. Lee, T.-H. Lim, S.-J. Park, R.-H. Song, et al., Fabrication and Operation of Tubular Segmented-In-Series (SIS) Solid Oxide Fuel Cells (SOFC), Fuel Cells. 12 (2012) 1099-1103. doi:10.1002/fuce.201200076.

[16] C.G. Fan, R.M. Wu, L.Z. Pei, Q.F. Zhang, Effect of Sintering Temperature on the Behavior of Oxygen Permeation for $\mathrm{La}_{0.6} \mathrm{Sr}_{0.4} \mathrm{Co}_{0.2} \mathrm{Fe}_{0.8} \mathrm{O}_{3-\delta}$ Tubular Membranes, Adv. Mater. Res. 105-106 (2010) 643646. doi:10.4028/www.scientific.net/AMR.105-106.643.

[17] Z. Liu, G. Zhang, X. Dong, W. Jiang, W. Jin, N. Xu, Fabrication of asymmetric tubular mixedconducting dense membranes by a combined spin-spraying and co-sintering process, J. Memb. Sci. 415-416 (2012) 313-319. doi:10.1016/j.memsci.2012.05.011.

[18] D.K. Ramachandran, M. Soggaard, F. Clemens, B.S. Sudireddy, A. Kaiser, Low cost porous MgO substrates for oxygen transport membranes, Mater. Lett. (2015).

[19] D.K. Ramachandran, F. Clemens, a. J. Glasscock, M. Søgaard, a. Kaiser, Tailoring the microstructure of porous $\mathrm{MgO}$ supports for asymmetric oxygen separation membranes: Optimization of thermoplastic feedstock systems, Ceram. Int. 40 (2014) 10465-10473. doi:10.1016/j.ceramint.2014.03.017.

[20] D.W. Ni, E. Olevsky, V. Esposito, T.T. Molla, S.P. V. Foghmoes, R. Bjørk, et al., Sintering of Multilayered Porous Structures: Part II-Experiments and Model Applications, J. Am. Ceram. Soc. 96 (2013) 2666-2673. doi:10.1111/jace.12374.

[21] C. Chatzichristodoulou, M. Sogaard, J. Glasscock, A. Kaiser, S.P.V. Foghmoes, P.V. Hendriksen, Oxygen Permeation in Thin, Dense Ce0.9Gd0.101.95- $\delta$ Membranes II. Experimental Determination, J. Electrochem. Soc. 158 (2011) F73. doi:10.1149/1.3559189.

[22] G. Pećanac, S. Foghmoes, M. Lipińska-Chwałek, S. Baumann, T. Beck, J. Malzbender, Strength degradation and failure limits of dense and porous ceramic membrane materials, J. Eur. Ceram. Soc. 33 (2013) 2689-2698. doi:10.1016/j.jeurceramsoc.2013.04.018.

[23] D. Ni, V. Esposito, C.G. Schmidt, T.T. Molla, K.B. Andersen, A. Kaiser, et al., Camber Evolution and Stress Development of Porous Ceramic Bilayers During Co-Firing, 978 (2013) 972-978. doi:10.1111/jace.12113.

[24] T. Tadesse, H. Lund, R. Bjørk, D.W. Ni, E. Olevsky, N. Pryds, Modeling kinetics of distortion in porous bi-layered structures, J. Eur. Ceram. Soc. 33 (2013) 1297-1305. doi:10.1016/j.jeurceramsoc.2012.12.019.

[25] A. Kaiser, A.S. Prasad, S.P. Foghmoes, S. Ramousse, N. Bonanos, V. Esposito, Sintering process optimization for multi-layer CGO membranes by in situ techniques, J. Eur. Ceram. Soc. 33 (2013) 549-556. doi:10.1016/j.jeurceramsoc.2012.09.021.

[26] J. Baber, A. Klimera, F. Raether, In situ measurement of dimensional changes and temperature fields during sintering with a novel thermooptical measuring device, 27 (2007) 701-705. doi:10.1016/j.jeurceramsoc.2006.04.043. 
[27] T.T. Molla, D.K. Ramachandran, D.W. Ni, F. Teocoli, A. Kaiser, N. Pryds, et al., Constrained Sintering of Bi-layered Tubular Structures, J. Eur. Ceram. Soc. 3 (2015) 941-950.

doi:doi:10.1016/j.jeurceramsoc.2014.10.010.

[28] D.K. Ramachandran, K. Kwok, M. Søgaard, F. Clemens, A.J. Glasscock, A. Kaiser, The role of sacrificial fugitives in thermoplastic extrusion feedstocks on properties of $\mathrm{MgO}$ supports for oxygen transport membranes, J. Eur. Ceram. Soc. 5 (2014) 1527-1537.

[29] W. Dong, H. Roh, Z. Liu, K. Jun, S. Park, Hydrogen Production from Methane Reforming Reactions over Ni / MgO Catalyst, 22 (2001) 1323-1327.

[30] N. Oishi, A. Atkinson, N.P. Brandon, J.A. Kilner, B.C.H. Steele, Fabrication of an anode-supported gadolinium-doped ceria solid oxide fuel cell and its operation at 550oC, J. Am. Ceram. Soc. 88 (2005) 1394-1396.

[31] T. Ramos, M. Sogaard, M.B. Mogensen, Electrochemical Characterization of Ni/ScYSZ Electrodes as SOFC Anodes, J. Electrochem. Soc. 161 (2014) F434-F444. doi:10.1149/2.045404jes.

[32] C. Chatzichristodoulou, M. Solgaard, P. V. Hendriksen, Oxygen Permeation in Thin, Dense Ce0.9Gd0.101.95- $\delta$ Membranes I. Model Study, J. Electrochem. Soc. 158 (2011) F61. doi:10.1149/1.3556096. 
Table 1. Composition of NiO-CGO, dense (CGO-D) and porous (CGO-P) ethanol based suspensions.

\begin{tabular}{lccc}
\hline Components & $\begin{array}{c}\text { NiO-CGO (60:40) } \\
\text { (electrode layer-fuelside) }\end{array}$ & $\begin{array}{c}\text { CGO-D } \\
\text { Membrane layer }\end{array}$ & $\begin{array}{c}\text { CGO-P } \\
\text { (Porous backbone } \\
\text { layer- airside) }\end{array}$ \\
\hline $\begin{array}{l}\text { Nickel oxide } \\
\text { CGO (Low surface area) } \\
\text { pre-calcined at } 1000^{\circ} \mathrm{C}\end{array}$ & $5-6$ vol.\% & --- & --- \\
$\begin{array}{l}\text { Surfactant, PVP K10 } \\
\text { Graphite }\end{array}$ & 3 vol.\% & 10 vol.\% & $4-5$ vol.\% \\
$\begin{array}{l}\text { Binder, PVB K90 } \\
\text { Viscosity @shear rate of } 100\end{array}$ & --- & 4 vol.\% & 5 vol.\% \\
(mPa.s) & 3 vol.\% & --- & 20 vol.\% \\
\hline
\end{tabular}

Table 2. The measured thicknesses of functional layers through SEM images

\begin{tabular}{ccccc}
\hline Layer & MgO & Ni-CGO & CGO-M & CGO-P \\
\hline $\begin{array}{c}\text { Thickness } \\
(\mu \mathrm{m})\end{array}$ & $819 \pm 11$ & $28 \pm 0.6$ & $31 \pm 0.5$ & $23 \pm 1.0$ \\
\hline
\end{tabular}


Fig. 1: (a) Schematic of the structure of the asymmetric tubular membrane including the used materials, (b) the thermoplastic extrusion of $\mathrm{MgO}$ tubes (black in green state due to graphite pore former) and the subsequent dip coating and firing steps with (c) MgO tube with dip coated Ni-CGO layer (brown, on left) and after pre-sintering at $\mathrm{T} 1=1250{ }^{\circ} \mathrm{C}$ (green, on right), (d) Dense CGO membrane layer after dip coating (DC) (white, on left) and sintering at $\mathrm{T} 2=1300^{\circ} \mathrm{C}$ (transparent on green NiO-CGO layer), (e) "porous" CGO layer after dip coating (black, on left) and after sintering at $\mathrm{T} 3=1250^{\circ} \mathrm{C}$ and infiltration (I) with LSC nano particles (blue, on right).

Fig. 2: De-bindering and sintering cycles used for co-sintering of tubular membrane.

Fig. 3: Schematic of membrane rig setup.

Fig. 4: Viscosity of various ceramic suspensions as function of shear rate.

Fig. 5: (a) Densification and (b) strain rates of CGO membrane (CGO-M) and $\mathrm{MgO}$ support (MgO-S) layers and, as well as strain rate difference between the two different layers for free sintering as function of sintering temperature. Measurements were performed at two different heating rates of $0.5{ }^{\circ} \mathrm{C} \min ^{-1}$ (dotted lines): and $3^{\circ} \mathrm{C} \mathrm{min}^{-1}$ (continuous lines) with an optical dilatometer TOMMI [32].

Fig. 6: SEM Micrographs of thermally etched surfaces of three different layers (a) full membrane, (b) interface of the $\mathrm{Ni}-\mathrm{CGO}$ and $\mathrm{MgO}$ porous layer after reduction, (c) dense CGO layer, (d) porous NiO-CGO layer and (e) porous $\mathrm{MgO}$ layer.

Fig. 7: Flux as function of reciprocal temperature for different hydrogen/nitrogen mixtures. The numbers in the caption all refer to the inlet volume flow of hydrogen and nitrogen in the unit $\mathrm{Nml} \mathrm{min}^{-1}$.

Fig. 8: Flux as a function of reciprocal temperature for three measurement series. Before a high temperature heat treatment at $920^{\circ} \mathrm{C}$, after a high temperature treatment at $930{ }^{\circ} \mathrm{C}$ and finally after the high temperature treatment but after a redox-cycling (air for $24 \mathrm{~h}$ ) of the membrane component at 650 ${ }^{\circ} \mathrm{C}$. 


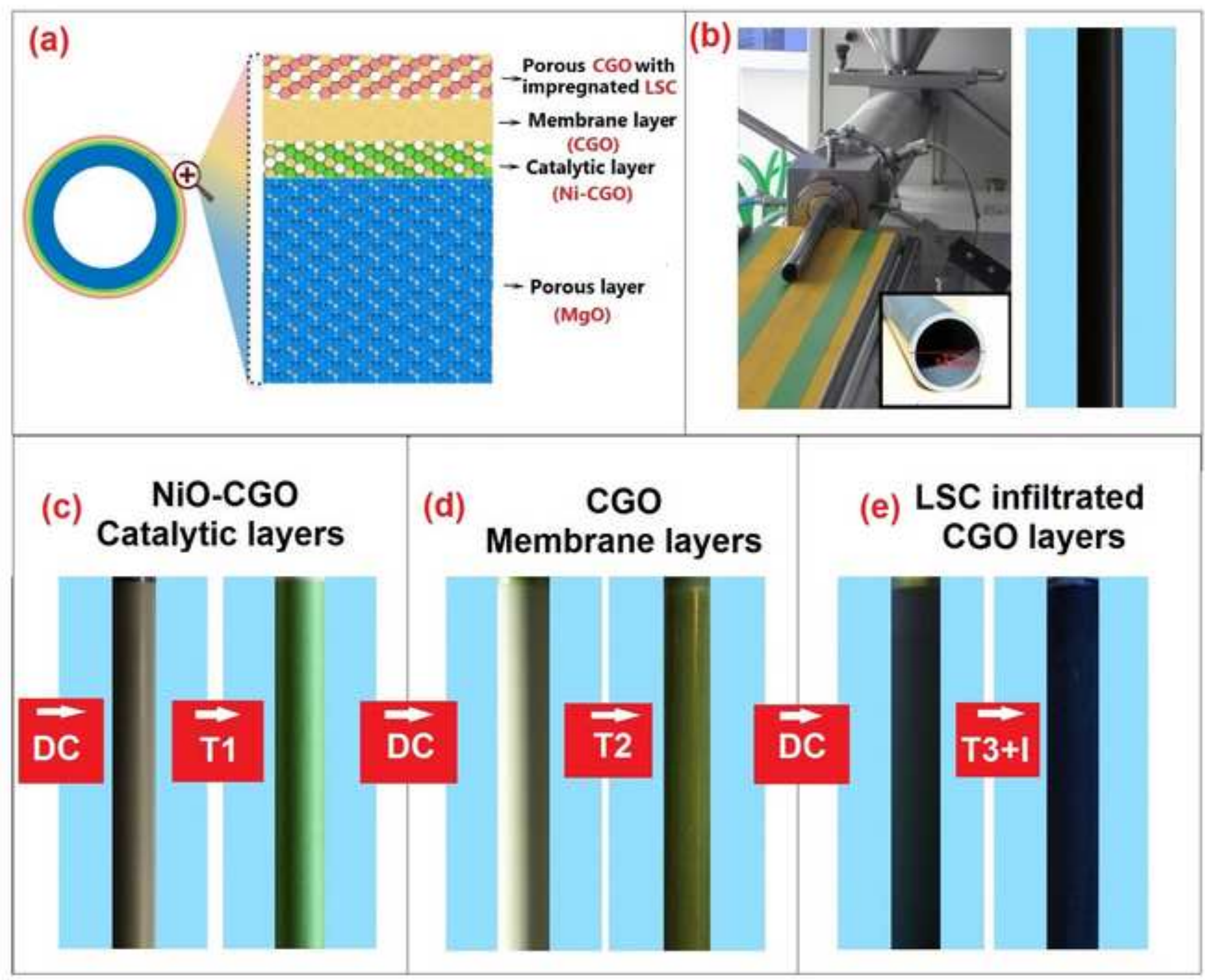




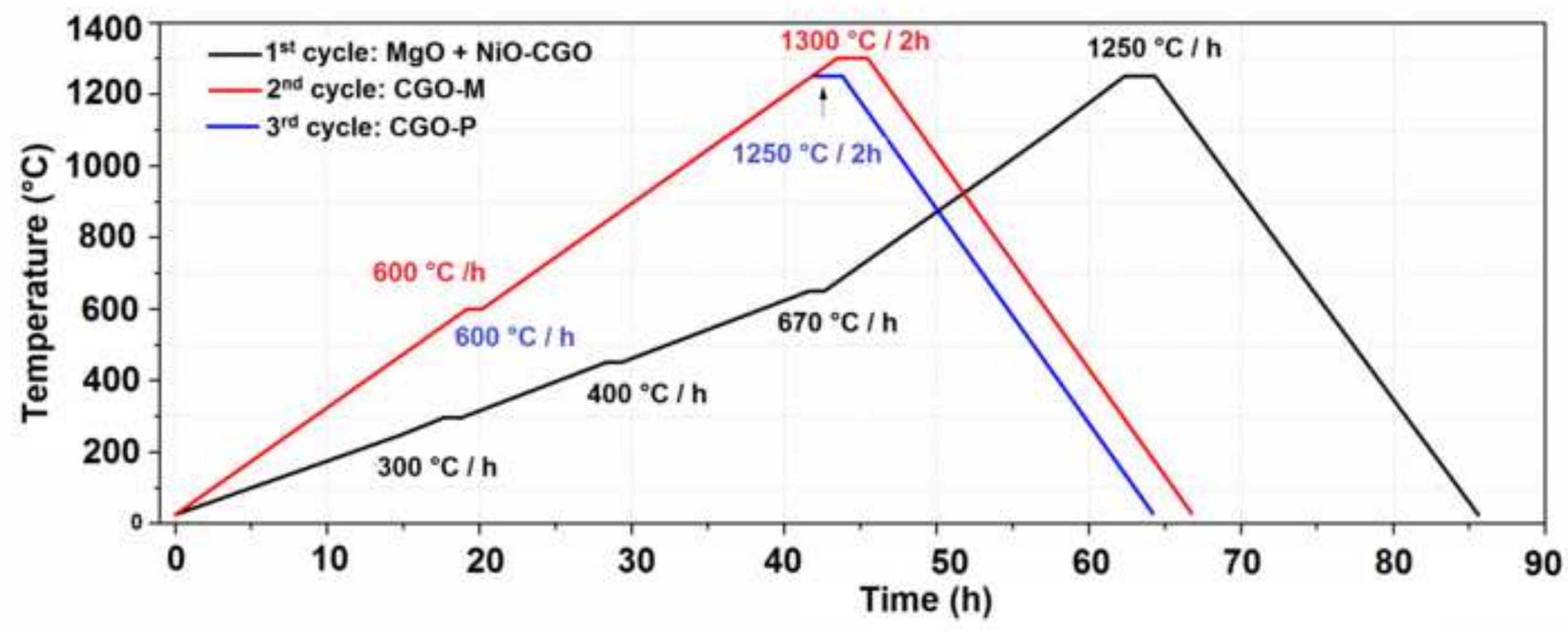


(6)

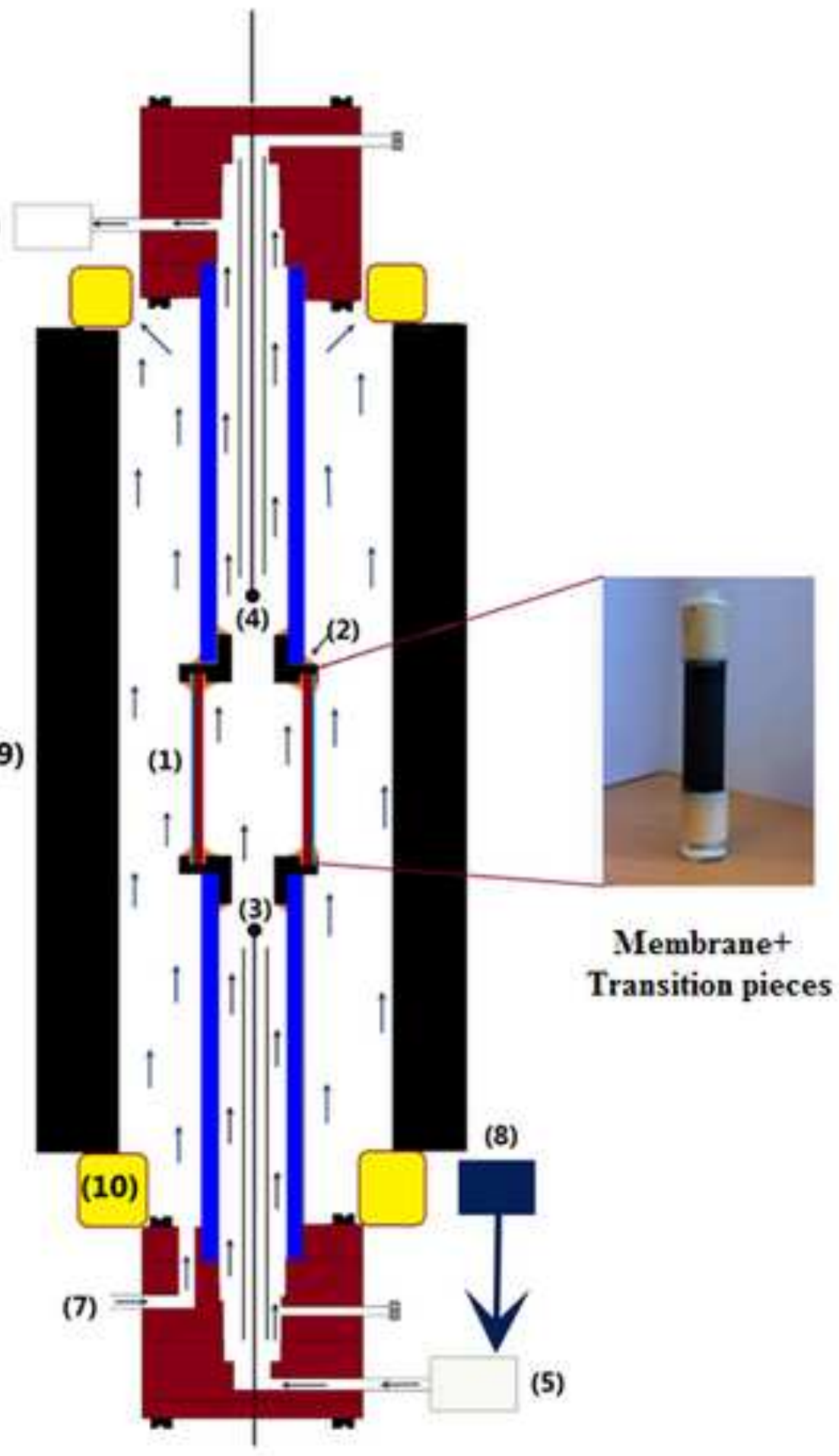

1. Membrane

2. Glass sealent

3. TC membrane inlet

4. TC membrane outlet

5. $\mathrm{pO}_{2}$ sensor-inlet
6. $\mathrm{pO}_{2}$ sensor-outlet

7. Feed inlet

8. Gas mixing panel

9. Furnace

10. Insulation 


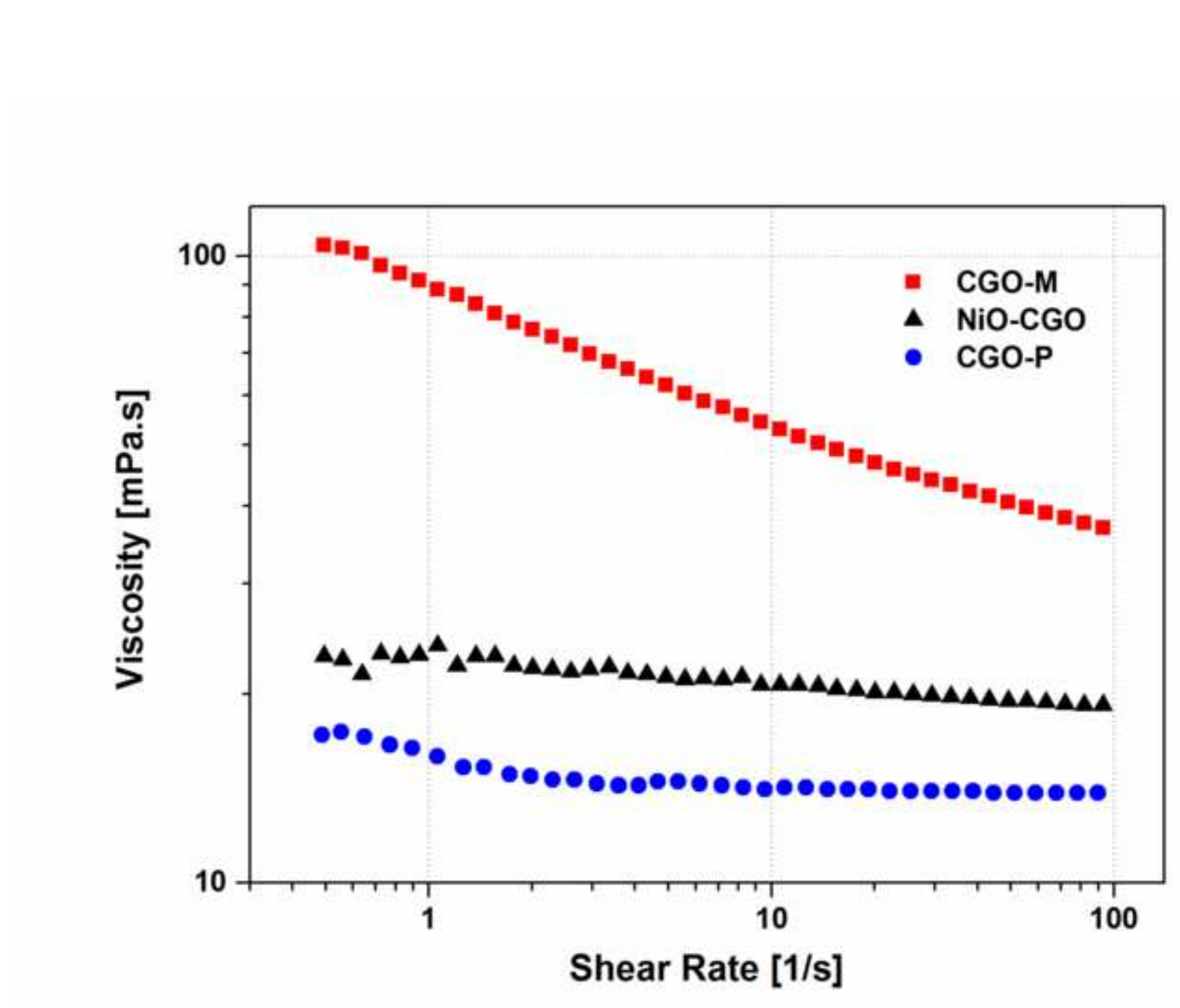

Shear Rate [1/s]

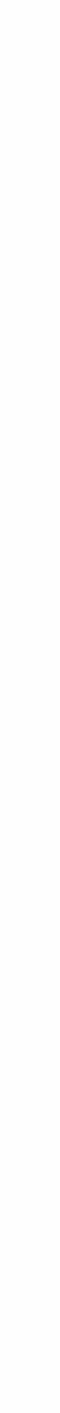


(a)

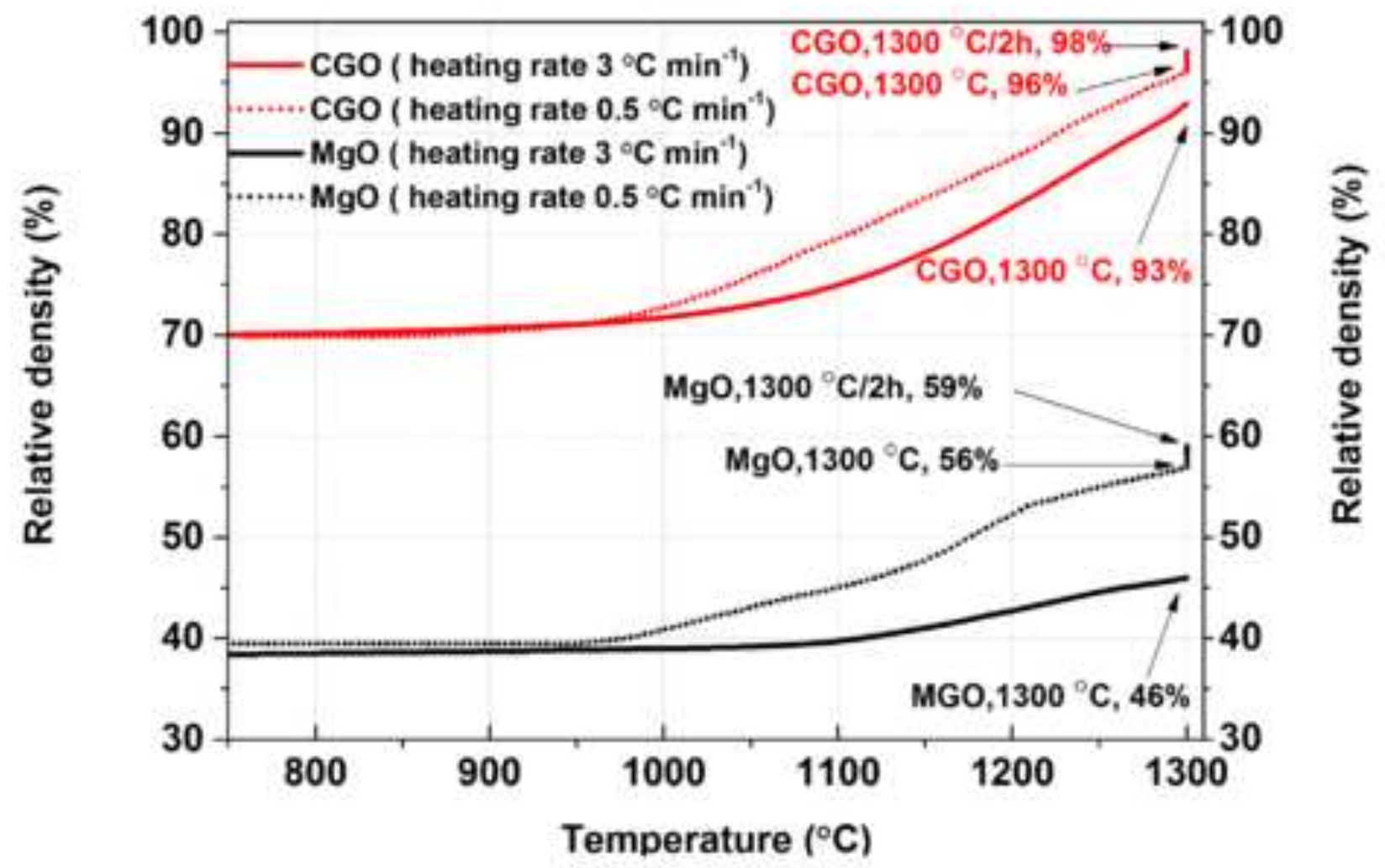

(b)

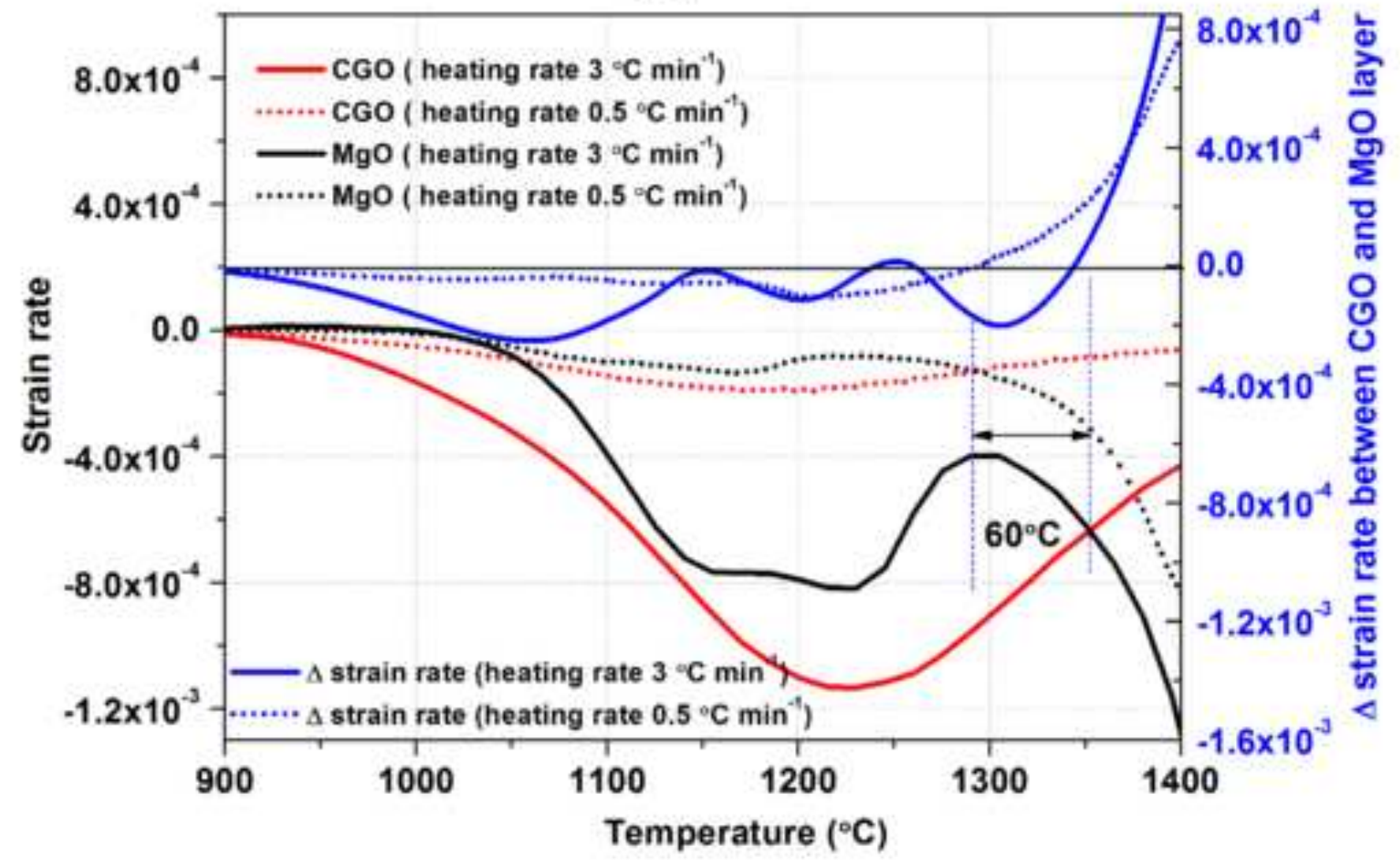




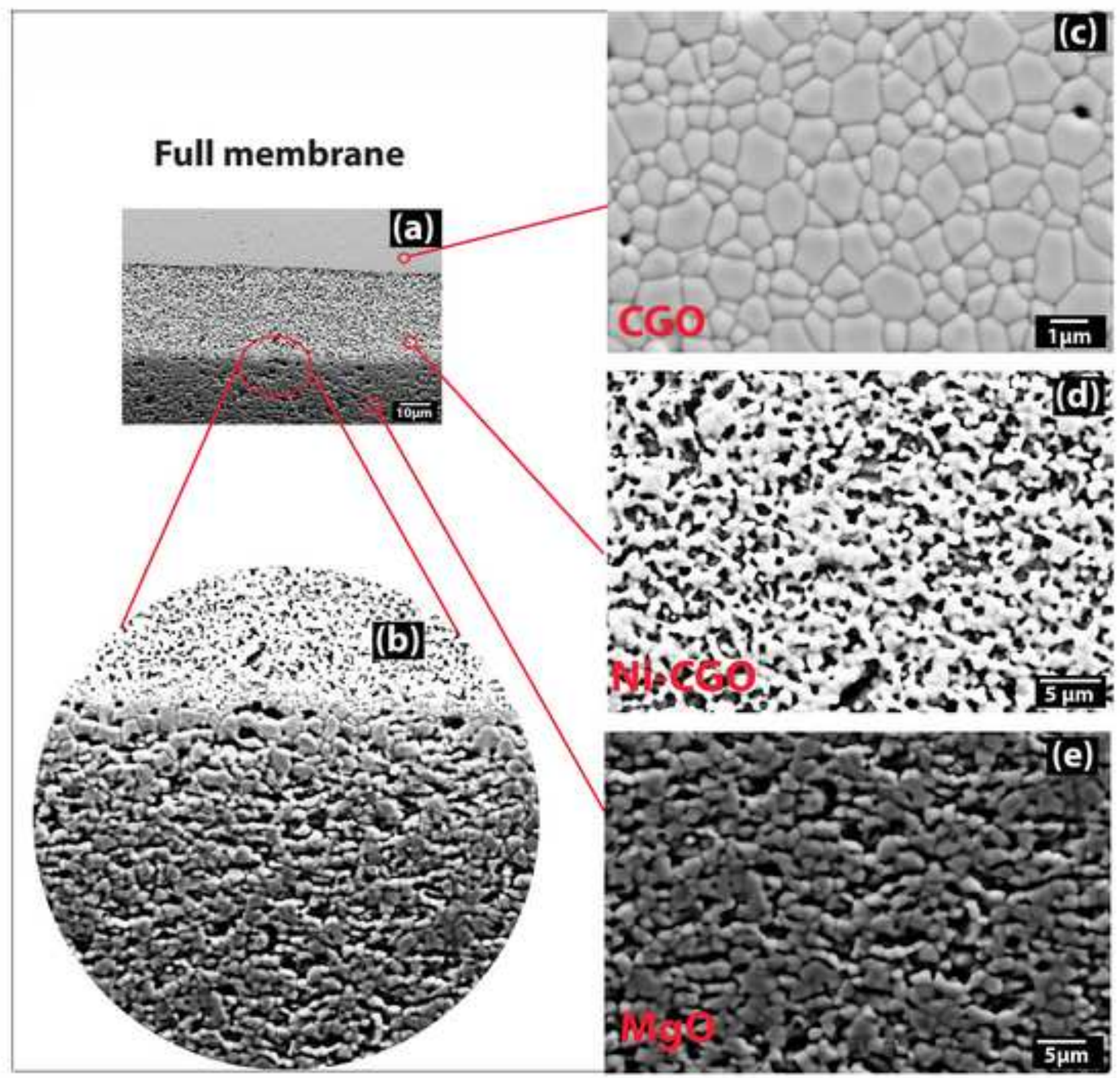




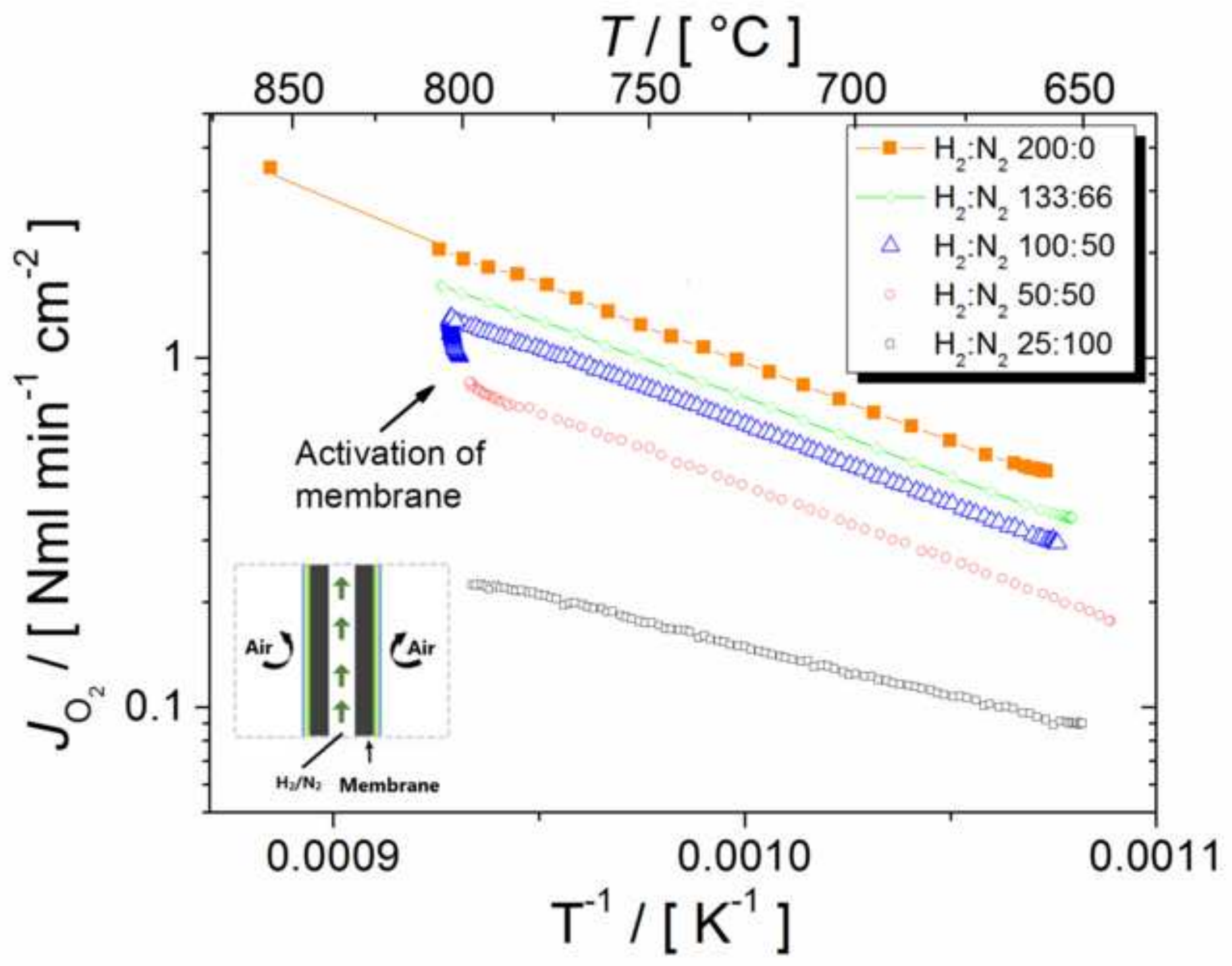




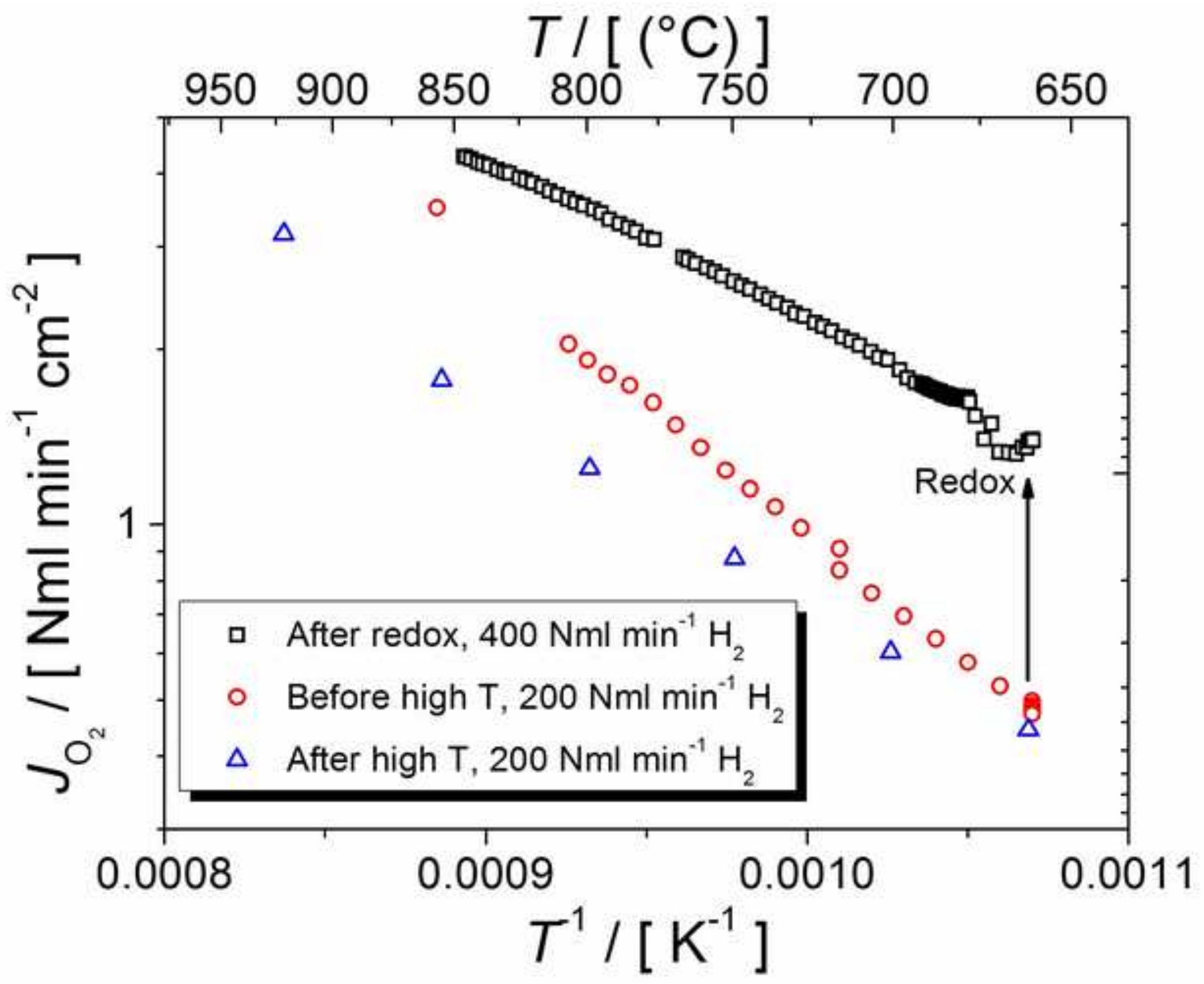

